NASA Technical Memorandum 4532

\title{
Identification of Integrated Airframe- Propulsion Effects on an F-15 Aircraft for Application to Drag Minimization
}

Gerard S. Schkolnik

Dryden Flight Research Facility

Edwards, California

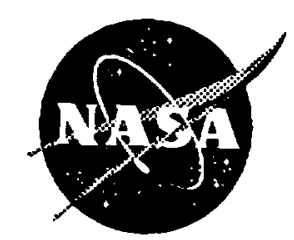

National Aeronautics and

Space Administration

Office of Management

Scientific and Technical Information Program 
$\ldots+\ldots$ 


\title{
IDENTIFICATION OF INTEGRATED AIRFRAME-PROPULSION EFFECTS ON AN F-15 AIRCRAFT FOR APPLICATION TO DRAG MINIMIZATION
}

\author{
Gerard S. Schkolnik* \\ NASA Dryden Flight Research Facility \\ Edwards, CA 93523
}

\begin{abstract}
The application of an adaptive real-time measurementbased performance optimization technique is being explored for a future flight research program. The key technical challenge of the approach is parameter identification, which uses a perturbation-search technique to identify changes in performance caused by forced oscillations of the controls. The controls on the NASA F-15 highly integrated digital electronic control (HIDEC) aircraft were perturbed using inlet cowl rotation steps at various subsonic and supersonic flight conditions to determine the effect on aircraft performance. The feasibility of the perturbation-search technique for identifying integrated airframe-propulsion system performance effects was successfully shown through fight experiments and postflight data analysis. Aircraft response and control data were analyzed postflight to identify gradients and to determine the minimum drag point. Changes in longitudinal acceleration as small as $0.004 \mathrm{~g}$ were measured, and absolute resolution was estimated to be $0.002 \mathrm{~g}$ or approximately $50 \mathrm{lbf}$ of drag. Two techniques for identifying performance gradients were compared: a least-squares estimation algorithm and a modified maximum likelihood estimator algorithm. A complementary filter algorithm was used with the least squares estimator.
\end{abstract}

\section{Nomenclature}

\section{Acronyms}

DEEC digital electronic engine control

HIDEC highly integrated digital electronic control

LSE least-squares estimator

MLE maximum likelihood estimator

\footnotetext{
Acrospace Engineer.

Copyright $\odot 1993$ by the American Institute of Acronautics and A stronautics, Inc. No copyright is asserted in the United States under Title 17, U.S. Code. The U.S, Government has a royalty-free license to exercise all rights under the copyright claimed herein for Govemmental purposes. All other rights are reserved by the copyright owner.
}

\author{
pEst \\ parameter estimation (NASA Dryden code) \\ PSC performance seeking control \\ Symbols \\ $a$ \\ estimated coefficient of output series in least-
squares analysis \\ ALT pressure altitude, $\mathrm{ft}$ \\ $\boldsymbol{b}$ \\ estimated coefficient of input series in least- \\ squares analysis \\ $C_{L} \quad$ total lift coefficient \\ $C_{m} \quad$ total pitching moment coefficient \\ $C_{m_{0}} \quad$ pitching moment coefficient bias \\ $C_{m_{\alpha}}$ \\ $C_{m_{s},}$ \\ derivative of pitching moment coefficient \\ with respect to angle of attack, $\mathrm{deg}^{-1}$ \\ derivative of pitching moment coefficient \\ with respect to symmetric cowl deflec- \\ tion, $\mathrm{deg}^{-1}$ \\ derivative of pitching moment coefficient \\ with respect to stabilator deflection, \\ $\operatorname{deg}^{-1}$ \\ $C_{m} \quad$ derivative of pitching moment coefficient \\ with respect to pitch rate, $\mathrm{rad}^{-1}$ \\ $C_{x} \quad$ total longitudinal force coefficient \\ $C_{x_{0}} \quad$ longitudinal force coefficient bias \\ $C_{x_{a}}$ \\ derivative of longitudinal force coefficient \\ with respect to angle of attack, $\mathrm{deg}^{-1}$ \\ $C_{x_{\delta}} \quad$ derivative of longitudinal force coefficient \\ with respect to symmetric cowl deflec- \\ tion, deg $^{-1}$
}




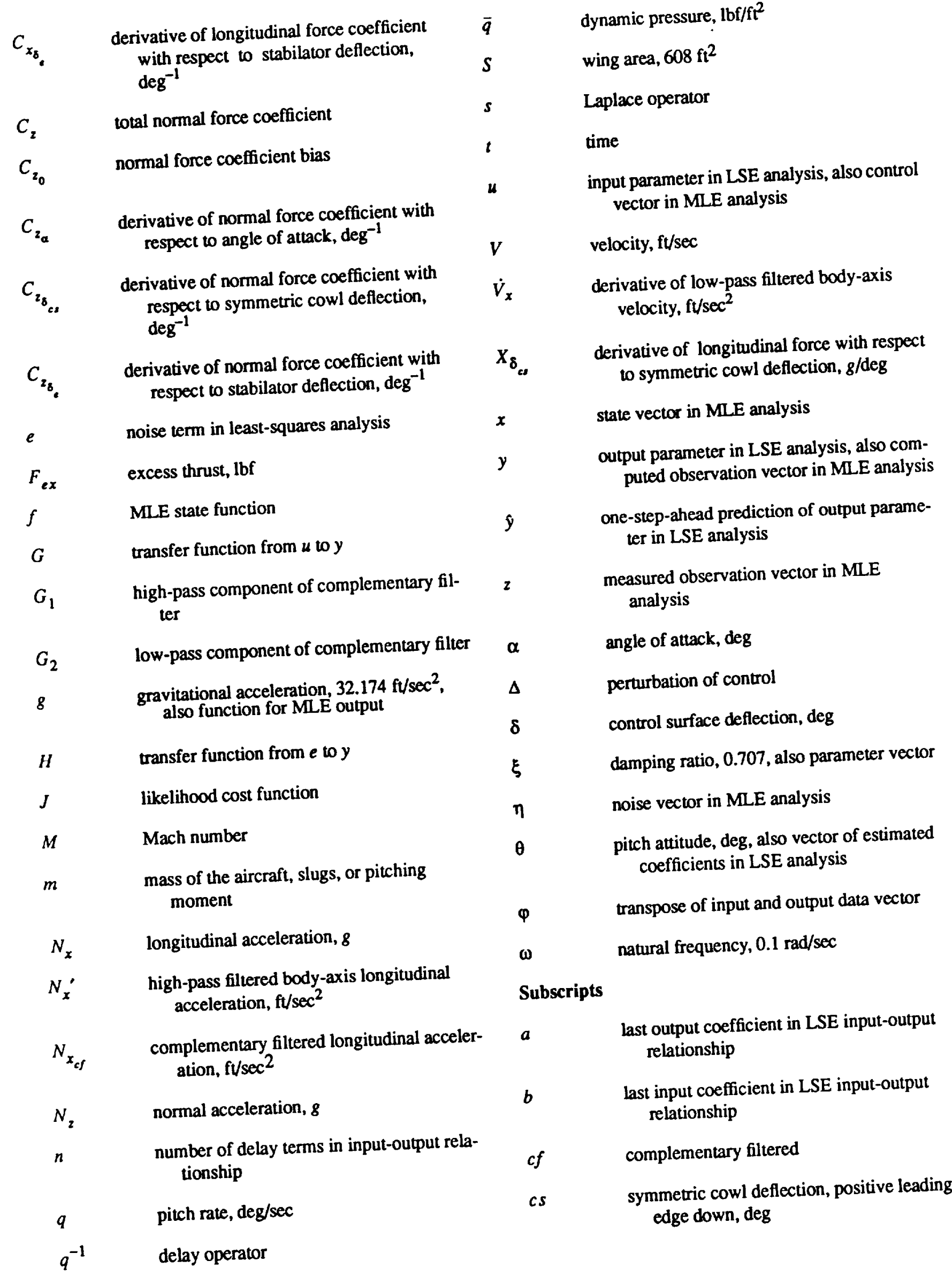


$m$

0

\section{Superscripts}

$T$

transpose

\section{Introduction}

For over a decade, the NASA Dryden Flight Research Facility has conducted a multidisciplinary performance improvement flight research program on an F-15 aircraft. Significant parts of this research involved the flight evaluation of advanced propulsion control concepts in programs such as digital electronic engine control (DEEC), 1,2 the F100 engine model derivative (EMD), ${ }^{3}$ and highly integrated digital electronic control (HIDEC), ${ }^{4,5}$ The increased performance and improved fuel economy shown on the F-15 HIDEC research vehicle led to the performance seeking control (PSC) program in which adaptive optimization of the near steady-state performance of an aircraft-propulsion system was addressed.

The PSC approach computed and applied incremental trims to the aircraft-propulsion control system input command schedule to enhance the performance of the aircraft. 6,7 The PSC control law included an estimation process using a Kalman filter to update the onboard engine model to represent the actual engine hardware better. The optimization process used linear-programming techniques to determine the optimal engine operating condition for the selected performance measure (Fig. 1). Although the PSC algorithm showed substantial benefits, there were inherent shortcomings. The PSC approach to optimizing aircraft performance consisted of a model-based, openloop algorithm. The algorithm relied heavily on accurate models of airframe, engine, inlet, and nozzle for the optimization process. No intrinsic means in the PSC approach could compensate for errors in modeling and measurements. The Kalman-filter estimator depended on accurate engine measurements and could not account for biases in those measurements. 8

Extensive testing of the PSC algorithm for the subsonic phase and preliminary testing of the supersonic phase have already been successfully conducted. ${ }^{9,10,11}$ Flight test results have validated predicted improvements in fuel efficiency, increases in thrust, and reductions in fan turbine inlet temperature leading to longer engine life.

The subsonic phase of the PSC program dealt exclusively with engine optimization, while the supersonic phase included inlet and stabilator integration. Optimization was based on models of the engine, nozzle, and inlet and a predicted minimum drag relationship between the inlet cowl and the stabilator. The adaptive features of PSC dealt only with the engine model and did not address updating of inlet or airframe model characteristics. An altitude control outer loop indirectly controlled the stabilator.

To address many technical shortcomings of the PSC approach, NASA Dryden is studying augmenting the realtime optimization problem with flight measurements and feedback control. ${ }^{12}$ The necessity for costly, high-fidelity engine and aircraft models required for the PSC program has been lessened by using a direct measurement approach that determines the sensitivity of the performance parameter-i.e., excess thrust or range factor-to control perturbations (aircraft and propulsion). Figure 2 depicts the direct measurement approach applied to drag minimization on the F-15 aircraft. Total aircraft drag is plotted as a function of stabilator position and cowl position for a given cruise condition. The scheduled operating point of the cowl dictates a certain stabilator position to maintain trim at the cruise condition. If a perturbation-search technique is applied to the cowl to identify the performance gradient, the cowl can be trimmed, forcing the stabilator to a new trim position, resulting in a lower total drag configuration (higher excess thrust).

The advanced airframe-propulsion technology control system concept, which uses this direct measurement approach, is divided into four major components: an executive module, excitation module, parameter identification module, and controller (Fig. 3). The executive provides most importantly the fault detection logic such as channel comparisons and output limit checking. The executive also serves as the distribution point for all needed data to the other three modules. The excitation module sizes the perturbation signals-i.e., duration, amplitude, and frequency-based on information received from the executive. The parameter identification module forms the partial derivatives of the performance parameter with respect to the controls. The controller receives the partial derivatives of the performance parameter with respect to the controls and applies trims to the controls in the favorable direction of reduced drag and increased fuel economy.

Two major technical issues with this concept are its ability to identify the required performance sensitivity with explicit control excitation that is not objectionable or noticeable to the pilot and whether conventional sensors 
can measure the resulting effects. These abilities are considered necessary for a real-time adaptive system. As such, a postflight evaluation of these issues was performed at selected regions of the F-15 subsonic and supersonic envelope.

This paper presents the feasibility of adaptively measuring in-flight performance sensitivities based on identifying changes in excess thrust with inlet cowl position. Data for this study were generated from flight test of the NASA F-15 HIDEC aircraft. Two algorithms are compared for identifying performance gradients: a least-squares estimation (LSE) and a maximum likelihood estimation (MLE) algorithm. The paper also describes the use of a complementary filter algorithm to enhance the acceleration measurement for the LSE.

\section{Aircraft Description}

Performance sensitivity was studied on the NASA F-15A HIDEC research aircraft, S/N 835 (Fig. 4), which is a high-performance military fighter aircraft capable of speeds faster than Mach 2. Two F100 derivative (PW1128) afterburning turbofan engines power the NASA F-15 aircraft. The aircraft was modified with a digital electronic flight control system. More information on the F-15 can be found in Ref. 1 .

The PW 1128 engine is a low-bypass ratio, twin-spool, afterburning turbofan technology demonstrator, derived from the F100-PW-100 engine. A full-authority DEEC similar to the one for current production F100-PW-220 engine controls the engines. The DEEC software has been modified to accommodate PSC trim commands, but the normal DEEC control loops (i.e., corrected fan speed and engine pressure ratio) were not modified. The DEEC trim commands for subsonic, nonafterburning conditions are perturbations on compressor inlet variable vanes, rear compressor variable vanes, corrected fan speed, and nozzle throat area. A more detailed description of the PW 1128 engine can be found in Ref. 3.

The NASA F-15 aircraft was also modified with an electronic air inlet controller that allows PSC trim commands to be added with first and third inlet ramp scheduled positions (Fig. 5). These inlet ramp schedules were tailored specifically for the PW1128 engines during supersonic flight to account for the higher engine airflow.

Longitudinal acceleration $\left(N_{x}\right)$ data were gathered from two longitudinal sensors, both flight test instrumentation. One accelerometer was in the noseboom, the other was near the center of gravity of the aircraft. The engineering unit ranges and resolutions of the accelerometers were \pm 1.37 and $\pm 1.03 \mathrm{~g}$ and 0.00268 and $0.00201 \mathrm{~g} / \mathrm{bit}$, respectively, using the aircraft's 10 -bit digital-to-analog instrumentation system. The aircraft also had the standard set of stability and control and airdata parameters measured. The data were recorded at 40 samples/sec, filtered and sampled down to 10 and 4 samples/sec for the postflight analysis.

\section{Analysis Method}

Two approaches were evaluated to identify the sensitivity of excess thrust with respect to changes in cowl position. The first method was a more direct approach, incorporating a one-degree-of-freedom, single-inputsingle-output LSE. To approximate the three-degree-offreedom problem as having only one degree of freedom, the following external constraints on pitching moment and lift coefficients were imposed:

$$
C_{m}=0
$$

and

$$
C_{L}=\text { constant }
$$

The implementation of these constraints is described in a later section, Flight Test Maneuver Description and Conditions.

The investigation assumed that changing the cowl position generates measurable performance changes. These performance changes result from a combination of aerodynamic forces and changes in engine thrust. This coupling defines the integrated nature of the problem. The inlet geometry dictates the pressure recovery seen by the engine, which strongly affects thrust. This coupling makes the problem difficult to model.

In trim, the total pitching moment coefficient, $C_{m}$, on the aircraft is zero.

$$
\begin{aligned}
C_{m}= & C_{m_{0}}+C_{m_{\alpha}} \alpha+C_{m_{q}} q+C_{m_{\delta}} \delta_{e} \\
& +C_{m_{c s}} \delta_{c s}=0
\end{aligned}
$$

$$
\begin{gathered}
\text { where } \\
C_{m_{0}}=\text { pitching moment coefficient bias } \\
C_{m_{\alpha}}=\begin{array}{l}
\text { derivative of pitching moment coefficient } \\
\text { with respect to angle of attack }
\end{array} \\
C_{m_{a}}=\begin{array}{l}
\text { derivative of pitching moment coefficient } \\
\text { with respect to pitch rate }
\end{array} \\
C_{m_{\delta}} \quad \begin{array}{l}
\text { derivative of pitching moment coefficient } \\
\text { with respect to stabilator deflection }
\end{array}
\end{gathered}
$$




$$
C_{m_{\mathrm{s}}}=\begin{aligned}
& \text { derivative of pitching moment coefficient } \\
& \text { with respect to symmetric cowl deflection }
\end{aligned}
$$

If the aircraft configuration and angle of attack are assumed to remain constant, then changes $(\Delta)$ in cowl deflection will cause a stabilator trim position change to maintain the total pitching moment coefficient equal to zero.

$$
\Delta \delta_{e}=-\Delta \delta_{c s} \frac{C_{m_{b_{c s}}}}{C_{m_{\delta}}}
$$

This new steady-state stabilator and cowl position is reflected in the longitudinal force coefficient, $C_{x}$, equation

$$
\begin{gathered}
C_{x}=C_{x_{0}}+C_{x_{\alpha}} \alpha+C_{x_{\delta}}\left(\delta_{e}+\Delta \delta_{e}\right) \\
C_{x_{c s}}\left(\delta_{c s}+\Delta \delta_{c s}\right)
\end{gathered}
$$

where

$$
C_{x_{0}} \quad=\text { longitudinal force coefficient bias }
$$$$
C_{x_{\alpha}}=\text { derivative of longitudinal force coefficient }
$$
with respect to angle of attack

$C_{x_{\delta_{e}}}=\begin{aligned} & \text { derivative of longitudinal force coefficient } \\ & \text { with respect to stabilator deflection }\end{aligned}$ $C_{x_{\delta_{c s}}}=\begin{aligned} & \text { derivative of longitudinal force coefficient } \\ & \text { with respect to symmetric cowl deflection }\end{aligned}$

and is directly measured by the longitudinal accelerometer

$$
N_{x_{m}}=\frac{\bar{q} S}{m g} C_{x}
$$

\section{Least Squares Estimator}

The linear, time-invariant system model was made second order with respect to the first ramp position because of the second-order nature of drag with respect to wing incidence angle. No dynamic elements were introduced into this model, since forces imparted to and by the cowl were assumed to result instantaneously in acceleration. The output parameter, $y(t)$, was chosen to be longitudinal acceleration.

$$
y(t)=b_{0}+b_{1} u(t)+b_{2} u^{2}(t)+e(t)
$$

where

$$
y(t)=N_{\substack{x_{c f} \\ \text { tion }}} \text { complementary longitudinal accelera- }
$$

$$
u(t)=\delta_{c s}, \text { symmetric cowl deflection (first ramp) }
$$

The Appendix develops the autoregressive exogenous model used for the LSE analysis. This model was chosen because it is a fast and uncomplicated algorithm that does not require an iterative solution. These characteristics allow the algorithm to be easily applied to a real-time system. Equation (5) shows the drag model used in the LSE analysis. The model consists of one output, three inputs (a constant, linear, and second-order term in $u(t)$ ), and no delays.

Once the coefficients are estimated, the linear dimensional derivative, with units of gravity per degree, can be obtained about the trim condition by differentiating equation (5) with respect to $u(t)$

$$
X_{\delta_{c s}}=\frac{\partial X}{\partial \delta_{c s}}=\frac{\partial y(t)}{\partial u(t)}=b_{1}+2 b_{2} u_{0}
$$

where $u_{0}=$ trim cowl position.

\section{Complementary Filter}

To enhance the observability of the output parameter in the LSE analysis, a complementary-filter algorithm was used during the postflight processing of this investigation. Complementary filters blend different sensor outputs to more accurately estimate the desired signal. For this investigation, corrected free-stream velocity, $V_{\text {inf }}$, an airdata parameter, and longitudinal acceleration, $N_{x}$, sensed by a force-balance accelerometer, were combined to produce a complementary-filtered longitudinal acceleration, $N_{x_{c f}}$, with the high-frequency characteristics of the acceleration sensor and the low-frequency characteristics of the rate sensor (Fig. 6). This complementary filter in effect eliminated the bias normally seen with conventional accelerometer data but retained the useful, high-frequency characteristics of the accelerometer.

The complementary filter used for this study was made second order. The philosophy behind the complementary filter is that numerator and denominator polynomial coefficients are identical, so the magnitude and phase characteristics remain unchanged.

$$
G(s)=\frac{s^{2}+2 \xi \omega s+\omega^{2}}{s^{2}+2 \xi \omega s+\omega^{2}}=1
$$

This polynomial is rewritten as the sum of two polynomials,

$$
G(s)=G_{1}(s)+G_{2}(s)
$$


where

$$
G_{1}(s)=\frac{s(s+2 \xi \omega)}{s^{2}+2 \xi \omega s+\omega^{2}}
$$

and

$$
G_{2}(s)=\frac{\omega^{2}}{s^{2}+2 \xi \omega s+\omega^{2}}
$$

By examining these polynomials, one sees that $G_{1}(s)$ resembles a high-pass filter and $G_{2}(s)$ resembles a lowpass filter. The sensor characteristics of the two sources of data used for the complementary filter match well with the attributes of the filter. The force balance accelerometer has a linear, high-frequency response but is subject to biases and low-frequency temperature drifts. The airdata velocity is based upon measured static and total pressures that can resolve very small changes but is subject to lag and attenuation when high-frequency pressure changes occur. It is natural, therefore, to pair the longitudinal accelerometer with $G_{1}(s)$ and the body-axis velocity with $G_{2}(s)$. To obtain compatible units with acceleration, the derivative of the body-axis velocity must be taken; this is easily done by multiplying $G_{2}(s)$ by $s$, so $G_{2}(s)$ becomes

$$
G_{2}(s)=\frac{s \omega^{2}}{s^{2}+2 \xi \omega s+\omega^{2}}
$$

The frequency and damping ratio of the complementary filter were selected to be $0.1 \mathrm{rad} / \mathrm{sec}$ and 0.707 , respectively, based on a brief study of the HIDEC instrumentation system.

\section{Maximum Likelihood Estimator}

The second method used in the study for comparison with the LSE method was an MLE. The MLE is a mathematically more precise probabilistic formulation than the LSE. For each possible estimate of the unknown parameters, a probability that the computed aircraft response time histories attain values near the measured values can be calculated. When the estimates are chosen to maximize the probability of occurring, this is the maximum likelihood estimate. Under certain conditions, the MLE has many desirable characteristics, such as yielding asymptotically unbiased and consistent estimates. If the measurement noise is assumed to be Gaussian, white, stationary, and uncorrelated, this formulation is equivalent to the LSE, where the weightings used are the inverse of the measurement noise covariance matrix. The MLE program used for the analysis was the NASA Dryden code, parameter estimation (pEst).
Figure 7 contains a block diagram of the program. Control inputs are sent to the aircraft model generating an estimated response. The estimated response of the aircraft model is subtracted from the measured response to produce the response error, which is sent to the MLE. The MLE has three components: a Gauss-Newton computational algorithm, cost function, and parameter estimates.

The Gauss-Newton computational algorithm is used to find the coefficient values that maximize the likelihood cost function. Each iteration of this algorithm provides revised estimates of the unknown coefficients based on the response error. The revised estimates of the coefficients are then used to update the aircraft model, providing a revised estimate response and, therefore, a revised response error. The mathematical model is updated iteratively until a convergence criterion is satisfied. For a more detailed discussion of the MLE approach and pEst see Refs. 14 to 17.

A simplified MLE approach contained a three-degreesof-freedom model that can estimate all longitudinal nondimensional derivatives or coefficients. The longitudinal aircraft equations can be written as follows:

$$
\begin{aligned}
& \dot{x}(t)=f[x(t), u(t), \xi] \\
& y(t)=g[x(t), u(t), \xi] \\
& z\left(t_{i}\right)=y\left(t_{i}\right)+\eta\left(t_{i}\right)
\end{aligned}
$$

where

$$
\begin{aligned}
& x(t)=\text { state vector } \\
& u(t)=\text { control vector } \\
& y(t)=\text { response vector } \\
& z\left(t_{i}\right)=\text { measured output vector } \\
& \eta\left(t_{i}\right)=\text { noise vector } \\
& \xi \quad=\text { parameter vector }
\end{aligned}
$$

In vector notation the state, control, and observation vectors can be written as follows:

$$
x=\left[\begin{array}{l}
q \\
\alpha \\
v \\
\theta
\end{array}\right], u=\left[\begin{array}{l}
\delta_{e} \\
\delta_{c s}
\end{array}\right] \text { and } y=\left[\begin{array}{c}
q \\
\alpha \\
V \\
N_{x} \\
N_{z}
\end{array}\right]
$$

The cost function can be defined as the integral squared error criterion and approximated in the discrete case as follows: 


$$
\begin{array}{r}
J(\xi)=\frac{1}{2 n_{2} n_{t}} \sum_{i=1}^{n_{1}}\left[\left(z\left(t_{i}\right)-\tilde{y}\left(t_{i}\right) T\right.\right. \\
\left.W\left[z\left(t_{i}\right)-\tilde{y}\left(t_{i}\right)\right]\right]
\end{array}
$$

where $n_{t}$ and $n_{z}$ are the number of time history points and response variables, respectively; $t$ is the time variable; $W$ is the response weighting matrix; $z$ is the measured response; $\bar{y}$ is the response computed by integrating the equations of motion; $\xi$ is the parameter vector, and superscript $T$ denotes transpose. To obtain maximum likelihood estimates for a given set of flight responses, the cost function, $J$, must be minimized. Since $2(t)$ is fixed for given flight responses, $J$ must be minimized by selecting the $\tilde{y}$ that minimizes $J$ where $\bar{y}$ is subject to the constraints of eq. (12).

The nondimensional aerodynamic model used for the analysis was the standard three-degrees-of-freedom model contained in the pEst program's equations of motion.

$$
\begin{aligned}
& C_{x}=C_{x_{0}}+C_{x_{\alpha}} \alpha+C_{x_{\delta}} \delta_{e}+C_{x_{\delta}, s} \delta_{c s} \\
& C_{z}=C_{z_{0}}+C_{z_{\alpha}} \alpha+C_{z_{\delta}} \delta_{e}+C_{z_{g} \delta_{c s}} \delta_{c s} \\
& C_{m}=C_{m_{0}}+C_{m_{\alpha}} \alpha+C_{m_{q}} q+C_{m_{g},} \delta_{e} \\
& +C_{m_{\mathrm{g} s}} \delta_{c s}
\end{aligned}
$$

Although it would have been easy to augment the model by introducing second-order terms in controls, linear terms were sufficient and valid about the trim condition. In practice, not all coefficients were estimated at once. At each flight condition, a conventional doublet was first analyzed to establish the basic stability and control coefficients or derivatives:

\begin{tabular}{|c|c:c:c|}
\hline & $\alpha$ & $\delta_{e}$ & $\vdots$ \\
\hline$m$ & $C_{m_{a}}$ & $C_{m_{s_{1}}}$ & $C_{m_{q}}$ \\
\hdashline$z$ & $C_{z_{a}}$ & $C_{z_{s_{1}}}$ & 0 \\
\hdashline$x$ & $C_{x_{a}}$ & 0 & 0 \\
\hline
\end{tabular}

These derivatives were then fixed during the analysis of the cowl step maneuver, and the remaining derivativesthe cowl control powers and biases - were estimated. This two-step approach prevented the dominant derivatives from trading with the cowl sensitivities.

\section{Flight Test Maneuver Description and Conditions}

To extract longitudinal acceleration gradients with respect to cowl deflections in flight required a well- conditioned maneuver. Extemal perturbations were minimized to achieve the most accurate identification. As mentioned in the Analysis Method section, two external constraints were maintained during the maneuver:

$$
C_{m}=0
$$

and

$$
C_{L}=\text { constant }
$$

For a given Mach number $(M)$ and constant altitude (ALT), both of the above equations were constrained. The constant altitude actually was obtained using the altitudehold autopilot mode when possible. The pilot selected the proper flight control mode, inlet integration, and trim values to be sent to both cowls simultaneously. Next, the pilot stabilized the aircraft on condition in a hands-off, 1-8 wings-level trim and engaged the autopilot. At this point, stabilized trim data were gathered; no other aircraft configuration changes were allowed. After approximately $30 \mathrm{sec}$ of stable data, the pilot would select the positive cowl trim for $30 \mathrm{sec}$. Afterward, the pilot deselected the positive trim and repeated the procedure with the negative trim.

Once the cowl step was completed a conventional longitudinal doublet usually was performed at the same conditions. The longitudinal doublet was used to estimate the lift and pitching moment derivatives of the aircraft at the conditions where the cowl step was performed. For the MLE analysis, these derivatives were held fixed to ensure that no residual forces entered the estimate. Figure 8 summarizes the test conditions flown for the investigation. Only three points were flown; however, they span the region of interest.

\section{Results and Discussion}

The cowl was perturbed on the NASA F-15 HIDEC aircraft at three flight conditions to determine sensitivities of excess thrust to cowl deflections. Flight data were analyzed postflight using two estimation algorithms for comparison purposes.

Figure 9 presents the results of a maneuver that exhibited the greatest change in excess thrust from the nominal schedule at a flight condition of Mach 1.25 at $25,000 \mathrm{ft}$. Time histories are presented for measured performance and state parameters (excess thrust $\left(F_{e x}\right), M$, ALT, $\alpha, \theta, q$, $N_{x}$, and $\left.N_{z}\right)$ and control parameters $\left(\delta_{c s}, \delta_{e}\right)$. Stabilized trim data were gathered for the first $20 \mathrm{sec}$. The steadystate value of measured $N_{x}$ was approximately $0.01 \mathrm{~g}$ indicating a bias in the sensor or that the aircraft was in a slightly accelerating condition before the perturbations. The nominal cowl deflection and stabilator trim position were $4.7^{\circ}$ and $4.3^{\circ}$, respectively. From 20 to $48 \mathrm{sec}$, the 
first trim of $-3^{\circ}$ was sent to the cowl, causing the autopilot to drive the stabilator $0.6^{\circ}$ trailing edge down to a new trim position of $4.9^{\circ}$. This reduced $N_{x}$ and $F_{\text {ex }}$ by $0.008 \mathrm{~g}$ and $500 \mathrm{lbf}$, respectively, and increased the trim drag on the aircraft. From 48 to $70 \mathrm{sec}$, the trim was removed and additional stabilized data were gathered. From 70 to 90 $\mathrm{sec}$, the last trim of $+3^{\circ}$ was sent to the cowl, causing the autopilot to drive the stabilator trailing edge up $0.55^{\circ}$ to a new trim position of $3.85^{\circ}$. This trim increased $N_{x}$ and $F_{\text {ex }}$ by $0.023 \mathrm{~g}$ and $800 \mathrm{lbf}$, respectively, and decreased the trim drag on the aircraft.

Since ride quality will limit the size of the disturbances from the desired flighpath, it is important to quantify the effects on ALT, $\alpha, \theta, q$, and $N_{z}$. Excursions of $14 \mathrm{ft}$ in ALT, $0.17^{\circ}$ in $\alpha, 0.48^{\circ}$ in $\theta, 0.3^{\circ} / \mathrm{sec}$ in $q$, and $0.05 \mathrm{~g}$ in $\mathrm{N}_{2}$ occurred because of the perturbation. The pilot did not detect the cowl excitation and its effects. Thus the perturbation required to implement an adaptive control system of the cowl would not distract the pilot or passengers.

Figure 10 shows plotted time histories of measured $N_{x_{c f}}$ and those computed using the estimated coefficients of the LSE algorithm. The computed and measured time histories match well with no bias or initial slope errors. In Fig. 11, time histories are plotted from measured flight data and computations made by the MLE algorithm (same maneuver as Fig. 9). In general, the histories match well. The computed time histories of $q$ show a small bias from the measured data, but this did not affect the coefficient estimates or uncertainty. The computed time histories of $N_{x}$ and $V$ fit well with the measured data. The LSE and MLE algorithms were shown to satisfactorily match output time histories for well-conditioned maneuvers.

Figure 12 presents the results of the subsonic maneuver that exhibited the smallest change in excess thrust $\left(F_{e x}\right)$ from the nominal schedule at a flight condition of 0.85 Mach and 35,000 ft. Time histories are presented for the following state parameters $\left(F_{e x}, M\right.$, ALT, $\alpha, \theta, q, N_{x}$, $\left.N_{z}\right)$, and control parameters, $\left(\delta_{c s}, \delta_{e}\right)$. Stabilized trim data were gathered from 0 to $8 \mathrm{sec}$. The steady-state value of $N_{x}$ was $0.031 \mathrm{~g}$ indicating that a bias was present or that the aircraft was slightly accelerating before the perturbations (which did not affect the results). The nominal cowl deflection and stabilator trim position were $4.8^{\circ}$ and $0.62^{\circ}$, respectively. From 8 to $45 \mathrm{sec}$, the first trim of $-3^{\circ}$ was sent to the cowl, causing the autopilot to drive the stabilator $0.23^{\circ}$ trailing edge down to a new trim position of $0.85^{\circ}$. This reduced $N_{x}$ and $F_{e x}$ by $0.006 \mathrm{~g}$ and $225 \mathrm{lbf}$, respectively, increasing the trim drag on the aircraft. From 49 to $67 \mathrm{sec}$, the trim was removed and additional stabilized data were gathered. From 71 to $97 \mathrm{sec}$, the last trim of $+3^{\circ}$ was sent to the cowl, again causing the autopilot to drive the stabilator trailing edge up $0.37^{\circ}$ to a new trim position of $0.25^{\circ}$. This trim increased $N_{x}$ and $F_{e x}$ by $0.004 \mathrm{~g}$ and $90 \mathrm{lbf}$, respectively, decreasing the trim drag on the aircraft.

This small change in $N_{x}$ was readily discernible in the time history and calculating a signal-to-noise ratio provided an estimate of the smallest measured change in $N_{x}$. This minimum was calculated to be $0.002 \mathrm{~g}$, which equates to approximately $50 \mathrm{lbf}$ of drag and coincides with resolution of the accelerometer. Note that the sinusoidal disturbance at a frequency of $0.32 \mathrm{~Hz}$ superimposed on the data was caused by an autopilot problem. Peak-to-peak changes of normal acceleration exceeded $0.40 \mathrm{~g}$ because of cyclical stabilator commands. As a result, it was thought at first that the data would be unusable. The postflight analysis, however, showed that both algorithms were robust to this type of disturbance and accurately estimated the gradients. For the LSE algorithm to be this robust was unexpected.

Figure 13 is a summary plot of the three maneuvers performed during the investigation. The dimensional derivative of longitudinal force coefficient with respect to cowl deflection is plotted as a function of Mach number. As was expected, the low dynamic pressure at the subsonic condition yields values close to zero, increasing as Mach number and dynamic pressure increase. Another area of interest that was not investigated is the mid-transonic regime, where difficulties in predicting an accurate cowl schedule could yield large gains over the baseline cowl schedule. There is overall agreement between the two analysis methods, MLE and LSE. The MLE approach has the added benefit of calculating Cramér-Rao bounds or uncertainty estimates that would benefit a real-time control system.

Figure 14 summarizes the demonstrated excess thrust benefits caused by incremental cowl rotation about its trim point. Although the data for the three maneuvers flown do not represent the optimum cowl-stabilator configuration, they illustrate the performance gains from the first iteration to the optimum. The maneuver at Mach 1.25 and $25,000 \mathrm{ft}$ clearly shows that more than $800 \mathrm{lb}$ of excess thrust were gained during the maneuver. The maneuver at Mach 1.6 and $35,000 \mathrm{ft}$ was limited to gains of approximately $250 \mathrm{lbf}$ of excess thrust caused by shock ingestion constraints, but the gradient was large and similar to the maneuver at Mach 1.25. The maneuver at Mach 0.85 and $35,000 \mathrm{ft}$ was significant because it alone demonstrated a change in sign of the gradient. Maximum excess thrust of $100 \mathrm{lbf}$ was estimated to occur at $8.5^{\circ}$, or $1^{\circ}$ up from the $9.5^{\circ}$ perturbation. 
The success encountered in this feasibility study shows that either method could be used for real-time adaptive control of the cowl and encourages further research to apply this approach to the engine itself. Given the similar results, faster computation, and easier implementation, the LSE method is more suitable for a real-time adaptive control environment. Further studies also can determine whether the performance sensitivities produced by perturbations of the engine controls, compressor-inlet variable vanes, rear-compressor variable vanes, and nozzle area can be identified.

\section{Concluding Remarks}

The cowl was perturbed on the NASA F-15 highly integrated digital electronic control aircraft at three flight conditions to determine sensitivities of excess thrust to cowl deflections. The flight data were analyzed postflight using two estimation algorithms to compare accuracy, speed, and ease of implementation into a real-time flight control system. The maneuvers were flown at three conditions, one subsonic and two supersonic.

The flight test results show that performance gradients always were identifiable with either method and that substantial benefits are possible over the baseline cowl schedules, particularly at high Mach numbers. Both approaches, the least squares estimator (LSE) and maximum likelihood estimator (MLE), produced similar results.

The MLE approach yields more information, including Cramér-Rao bounds, and contains a more complex threedegrees-of-freedom model that requires a more computationally intensive iterative solution. The LSE approach contains a one-degree-of-freedom model that can introduce more inaccuracies into the estimate but can be solved directly. More expertise also is needed to initialize the MLE algorithm to ensure proper convergence, as opposed to the LSE method.

Given the similar results, faster computation, and easier implementation, the LSE method appears more suitable for a real-time adaptive control environment. For adaptive implementation, only small perturbations that would not be noticed by either the pilot or passengers are required.

\section{References}

${ }^{1}$ Burcham, Frank W., Jr., Lawrence P. Myers, and Kevin R. Walsh, Flight Evaluation Results for a Digital Electronic Engine Control in an F-15 Airplane, NASA TM-84918, 1983.

${ }^{2}$ Digital Electronic Engine Control (DEEC) Flight Evaluation in an F-15 Airplane, Proceedings of a minisymposium held at NASA Dryden Flight Research
Facility, Edwards, California, May 25-26, 1983, NASA CP-2298.

${ }^{3}$ Myers, Lawrence P. and Frank W. Burcham, Jr., Preliminary Flight Test Results of the F100 EMD Engine in an F-15 Airplane, NASA TM-85902, 1984.

${ }^{4}$ Baer-Riedhart, Jennifer L. and Robert J. Landy, Highly Integrated Digital Electronic Control: Digital Flight Control, Aircraft Model Identification, and Adaptive Engine Control, NASA TM-86793, 1987.

${ }^{5}$ Highly Integrated Digital Electronic Control Symposium, Proceedings of a conference held at NASA Dryden Flight Research Facility, Edwards, California, March 1112, 1987, NASA CP-3024.

${ }^{6}$ Tich, EJ., P.D. Shaw, D.F. Berg, S. Adhibatla, J.A. Swan, and C.A. Skira, "Performance Seeking Control for Cruise Optimization in Fighter Aircraft," AIAA-87-1929, June 1987.

${ }^{7}$ Smith, R.H., J.D. Chisholm, and J.F. Stewart, “Optimizing Aircraft Performance with Adaptive, Integrated Flight/Propulsion Control," ASME-90-GT-252, June 1990.

${ }^{8}$ Espana, Martín D., "On the Estimation Algorithm for Adaptive Performance Optimization of Turbofan Engines," AIAA-93-1823, June 1993.

${ }^{9}$ Gilyard, Glenn B. and John S. Orme, "Subsonic Flight Test Evaluation of a Performance Seeking Control Algorithm on an F-15 Airplane," AIAA-92-3743, July 1992.

${ }^{10}$ Orme, John S. and Glenn B. Gilyard, "Flight Test Evaluation of the Propulsion System Parameter Estimation Process for the Performance Seeking Control Program," AIAA-92-3745, July 1992.

"Orme, John S. and Glenn B. Gilyard, "Supersonic Flight Test Evaluation of Performance Seeking Control," ALAA-93-1821, June 1993.

${ }^{12}$ Gilyard, Glenn B. and John S. Orme, "Performance Seeking Control: Flight Results and Future Direction," AIAA-93-3765, 1993.

${ }^{13}$ Ljung, Lennart, System Identification: Theory for the User, Prentice-Hall, Inc., New Jersey, 1987.

\footnotetext{
${ }^{14}$ Murray, James E. and Richard E. Maine, $p$ Est Version 2.I User's Manual, NASA TM-88280, Sept. 1987.
} 
${ }^{15}$ Iliff, K.W., “Maximum Likelihood Estimates of Lift and Drag Characteristics Obtained from Dynamic Aircraft Maneuvers," in Proceedings, AIAA 3rd Atmospheric Flight Mechanics Conference, Arlington, Texas, June 7-9, 1976.

${ }^{16}$ Maine, R.E. and Iliff, K.W., Application of Parameter Estimation to Aircraft Stability and Control: The Output-Error Approach. NASA RP-1168, June 1986.

${ }^{17}$ Klein, Vladislav, "Estimation of Aircraft Aerodynamic Parameters from Flight Data," Prog. Aerospace Sci., Vol. 26, 1989, pp. 1-77.

\section{Appendix}

The model structure used for the least squares analysis is described as the autoregressive exogenous (ARX) model where AR refers to the autoregressive part $A(q) y(t)$ and X refers to the extra input $B(q) u(t)$ called the exogenous variable. ${ }^{13}$ Figure 15 is the block diagram for the model. The general input-output relationship is described by the following linear difference equation where $n_{k}$ is equal to the number of delays from input to output:

$$
\begin{aligned}
y(t)+a_{1} y(t-1) & +\ldots+a_{n_{b}} y\left(t-n_{a}\right)= \\
& b_{1} u\left(t-n_{k}\right)+b_{2} u\left(t-n_{k}-1\right)+\ldots \\
& +b_{n_{b}} u\left(t-n_{k}-n_{b}+1\right)+e(t)
\end{aligned}
$$

The estimated coefficients are contained in the following vector:

$$
\theta=\left[\begin{array}{llll}
a_{1} & a_{2} \ldots a_{n_{a}} & b_{1} \ldots b_{n_{b}}
\end{array}\right]^{T}
$$

If we introduce

$$
A(q)=1+a_{1} q^{-1}+\ldots+a_{n_{q}} q^{-n_{0}}
$$

and

$$
B(q)=b_{1}+b_{2} q^{-1}+\ldots+b_{n_{b}} q^{-n_{b}+1}
$$

where $q^{-1}$ is the delay operator, we see that the general predictor model

$$
y(t)=G(q, \theta) u\left(t-n_{k}\right)+H(q, \theta) e(t)
$$

can be formed when

$$
G(q, \theta)=\frac{B(q)}{A(q)}, \quad H(q, \theta)=\frac{1}{A(q)}
$$

By definition, the noise characteristics of the LSE are Gaussian. Although it may not be intuitive that white noise is assumed to go through the denominator dynamics of the system before being added to the output, this model has a very important property that makes it a prime choice for many applications - the predictor defines a linear regression. This is shown below.

The one-step-ahead prediction for equation (23) is given by

$$
\begin{aligned}
\hat{y}(t \mid \theta)= & H^{-1}(q, \theta) G(q, \theta) u\left(t-n_{k}\right) \\
& +\left[1-H^{-1}(q, \theta)\right] y(t)
\end{aligned}
$$

Substituting equation (24) into (25) yields

$$
\hat{y}(t)=B(q) u\left(t-n_{k}\right)+[1-A(q)] y(t)
$$

Now introduce the vector

$$
\begin{aligned}
\varphi(t)= & {\left[-y(t-1) \ldots-y\left(t-n_{a}\right)\right.} \\
& \left.u\left(t-n_{k}\right) \ldots u\left(t-n_{k}-n_{b}+1\right)\right]^{T}
\end{aligned}
$$

Then equation (26) can be rewritten as

$$
\hat{y}(t \mid \theta)=\theta^{T} \varphi(t)=\varphi^{T}(t) \theta
$$

This predictor model is a linear regression composed of a scalar product between the known data vector $\varphi(t)$ and the parameter vector $\theta$. 


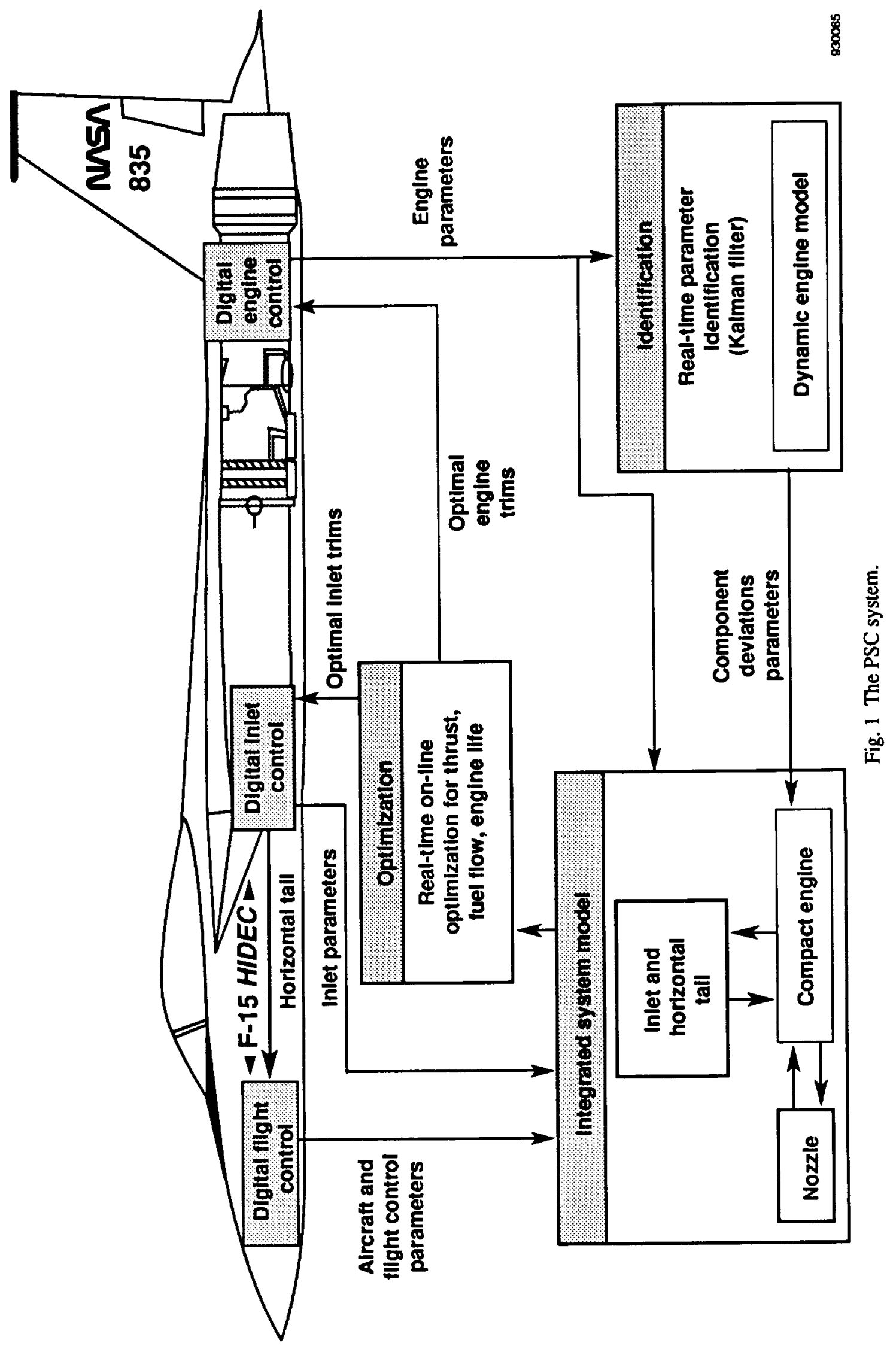




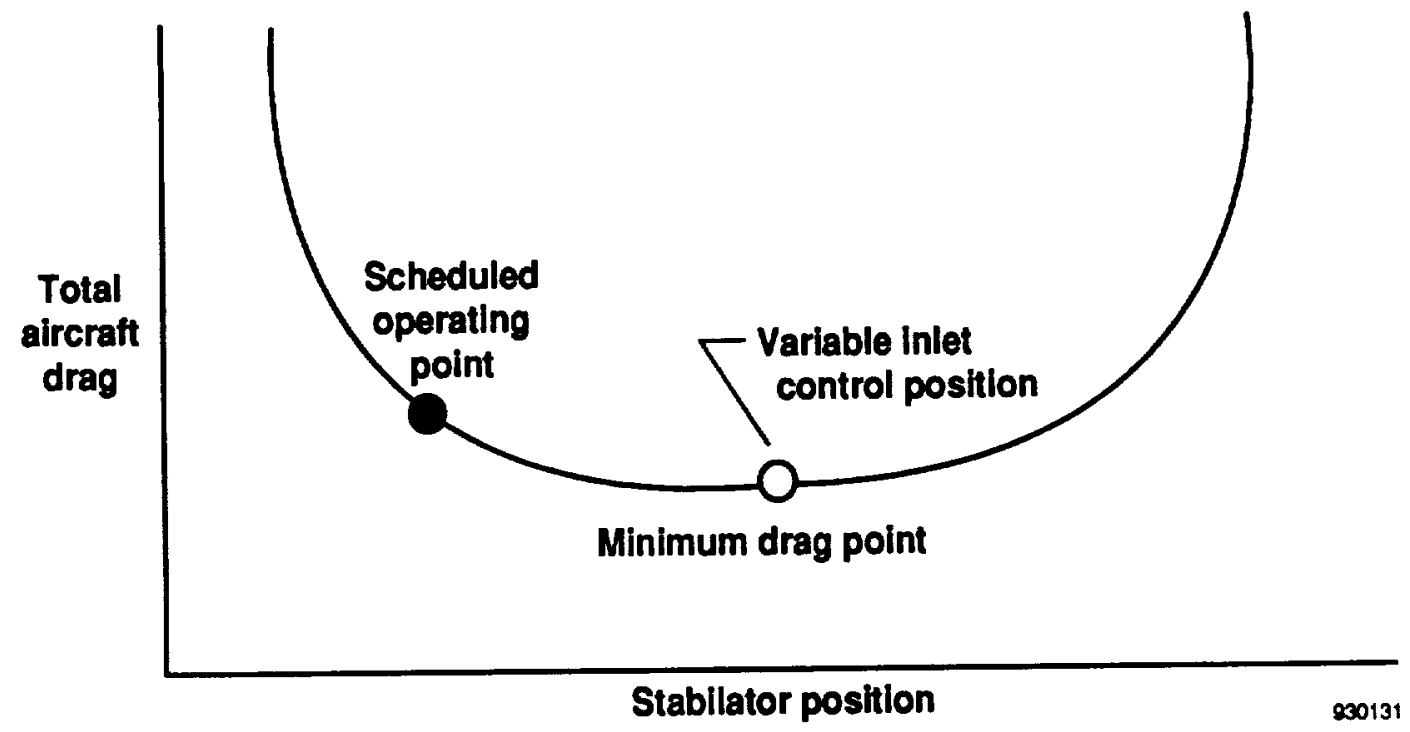

Fig. 2 Comparison of total aircraft drag to stabilator and cowl position. 


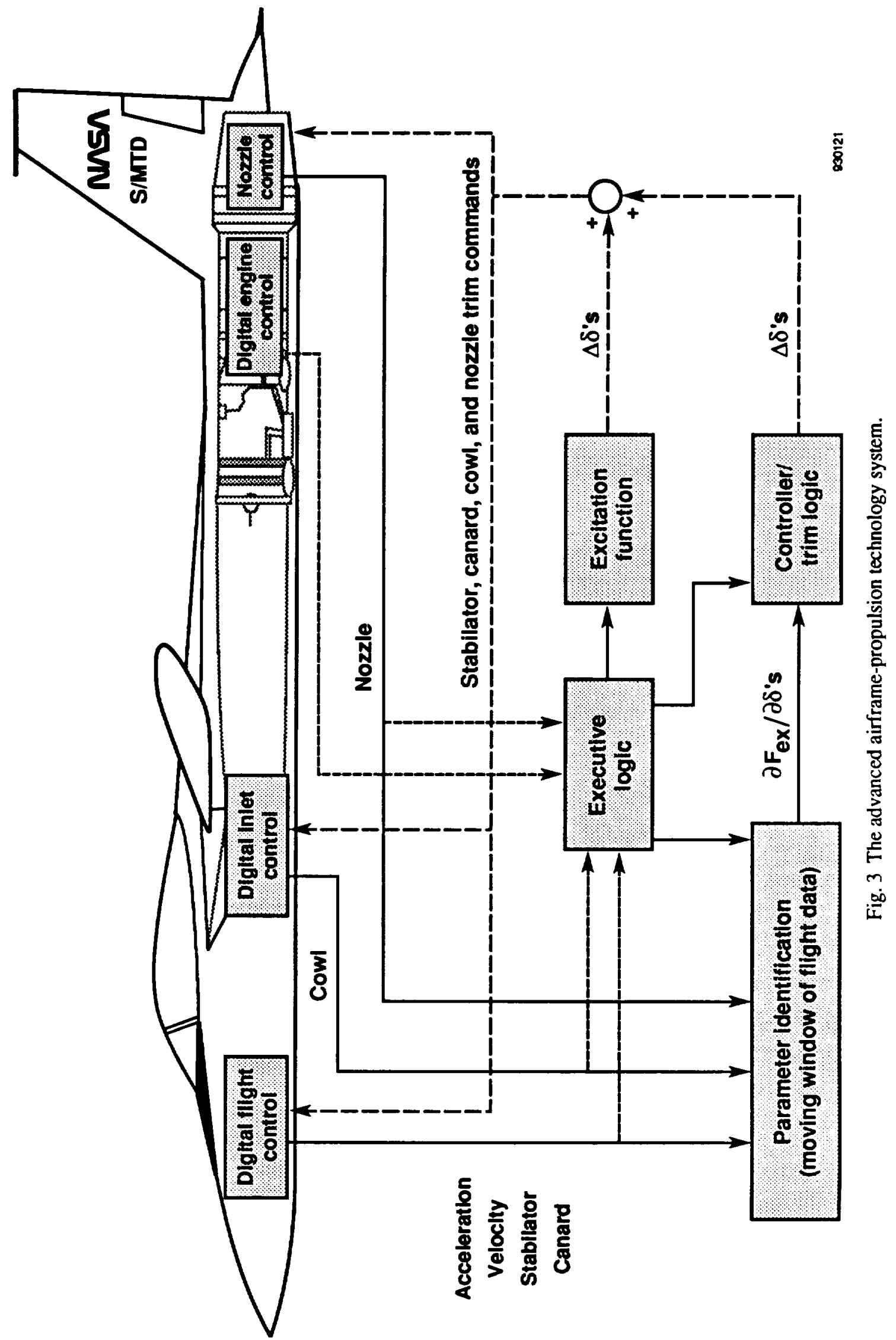




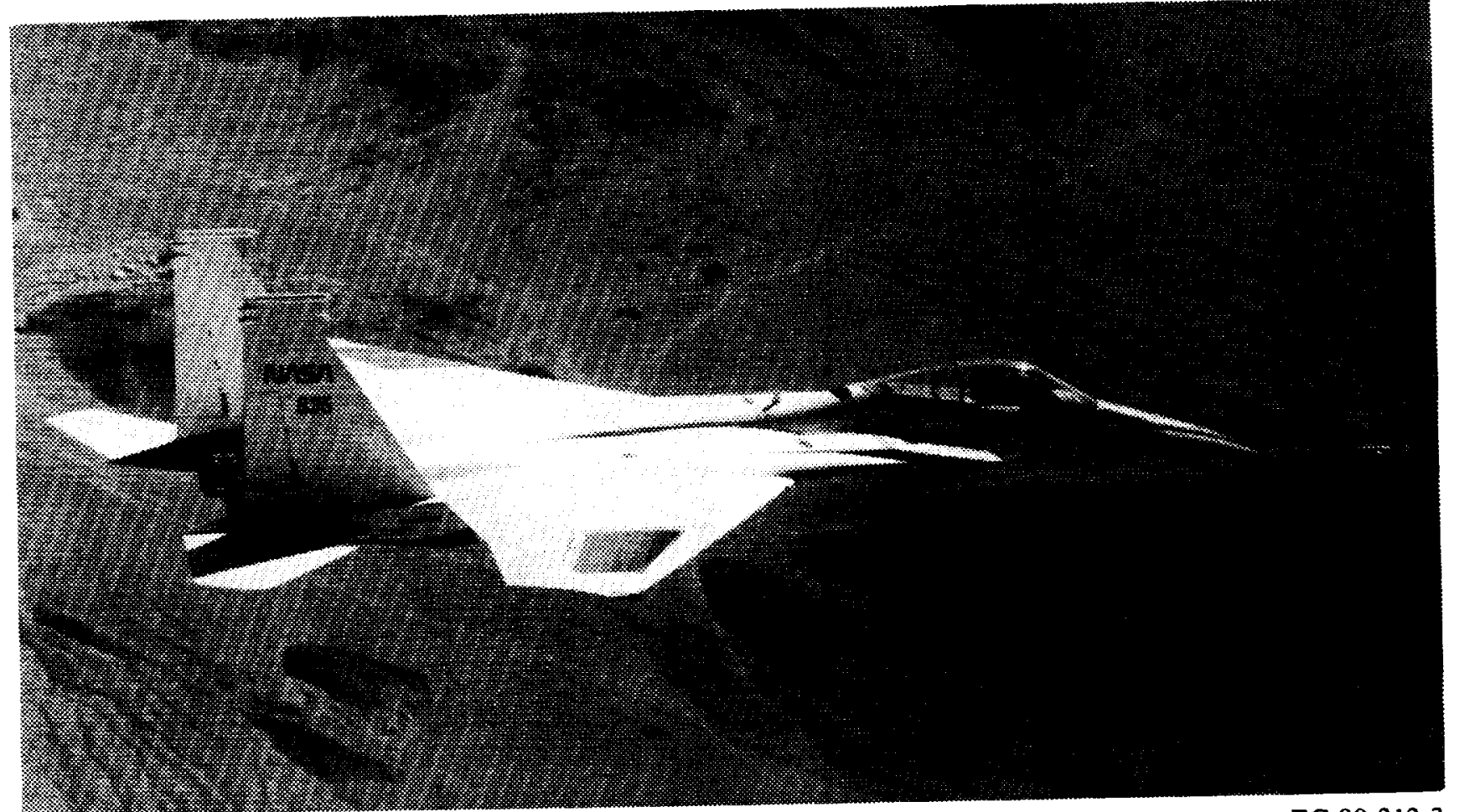

EC-90-312-3

Fig. 4 The NASA F-15 HIDEC aircraft.
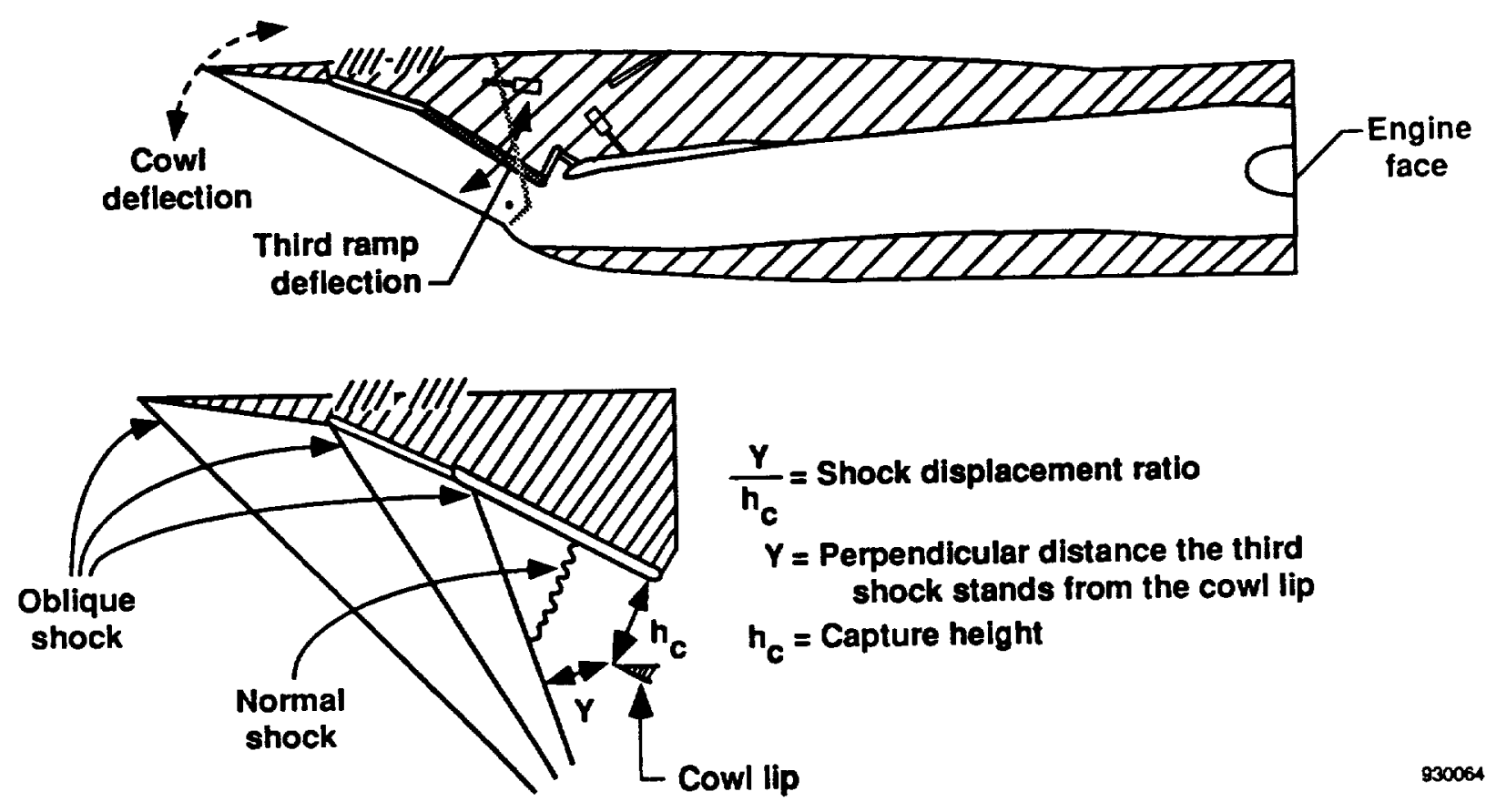

930064

Fig. 5 Side view of the F-15 inlet. 


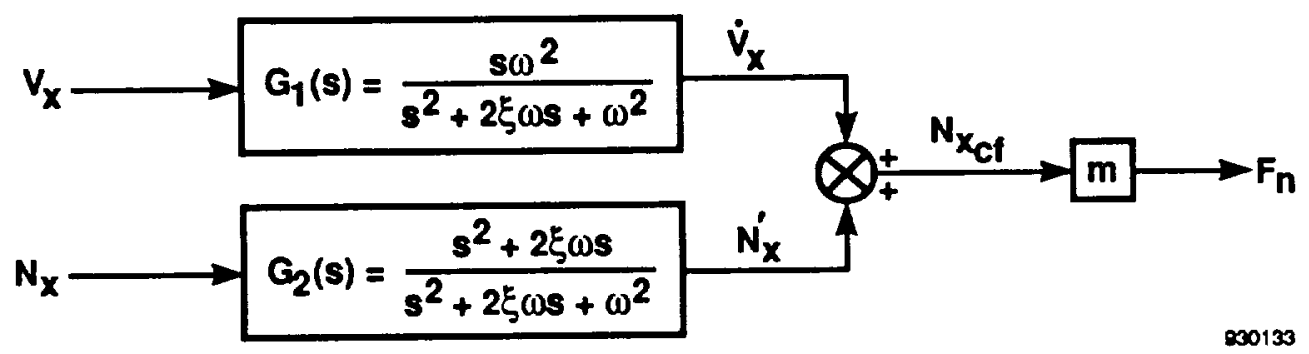

Fig. 6 The complementary filter.

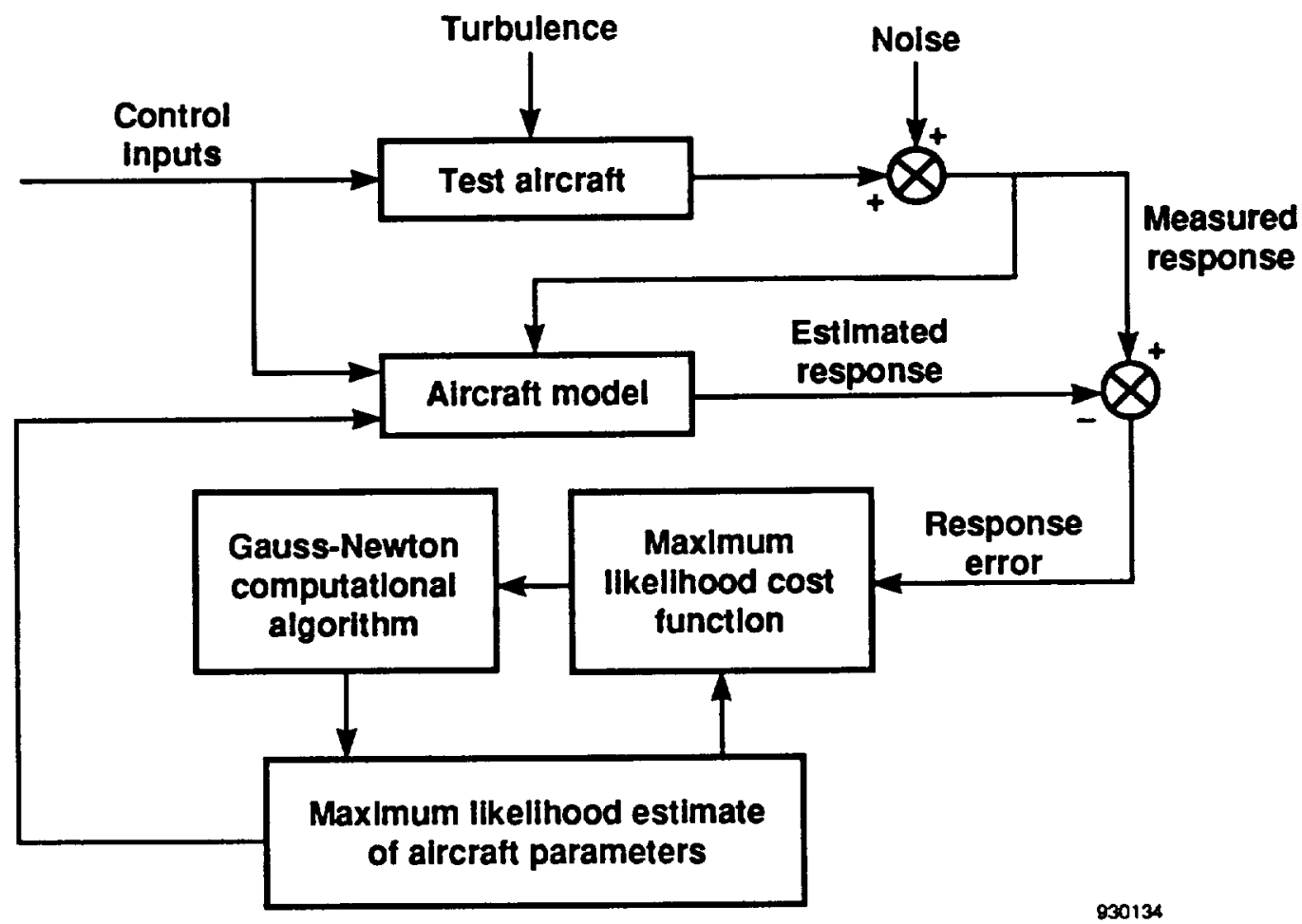

Fig. 7 The MLE model. 


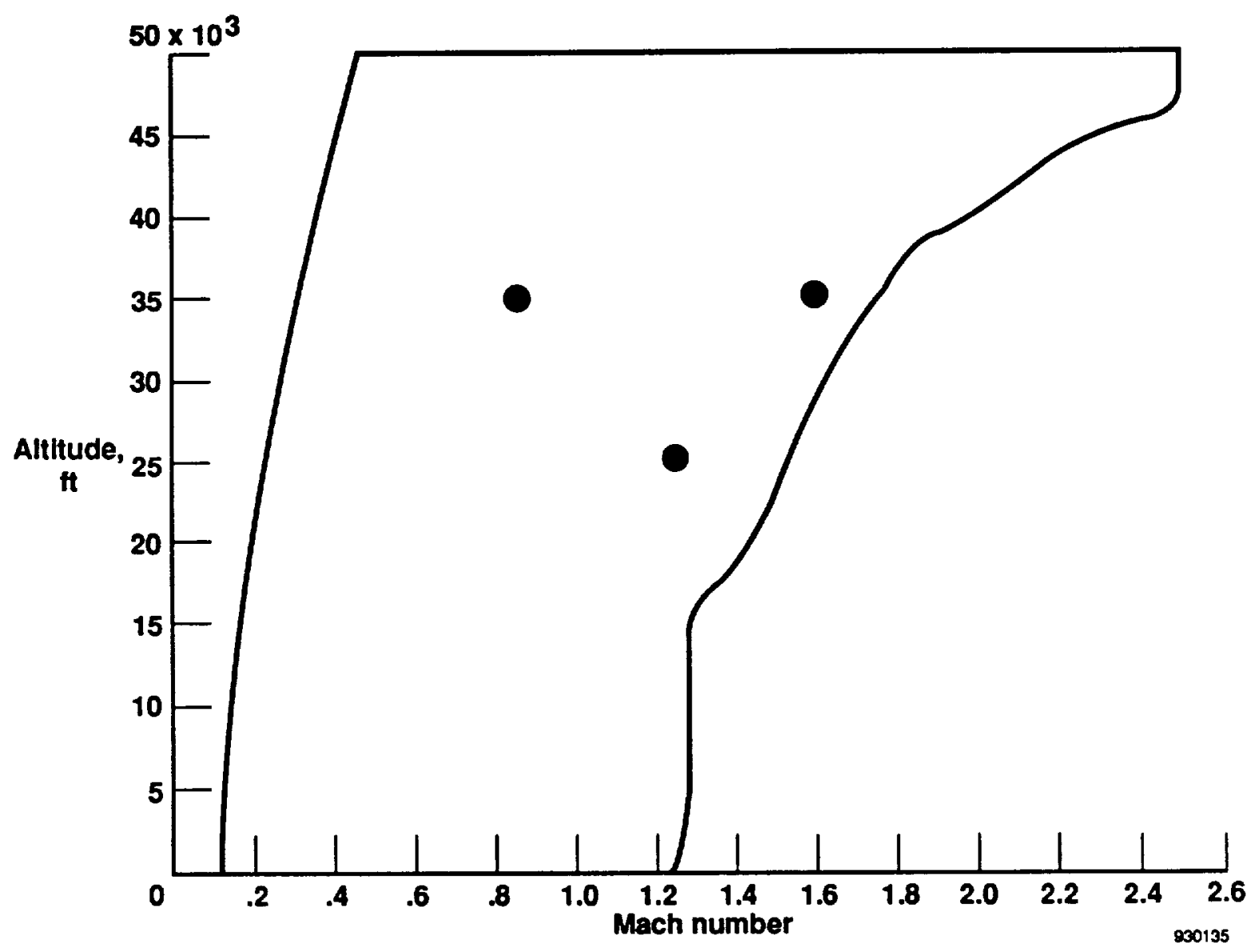

Fig. 8 Test conditions for the performance sensitivity feasibility study. 

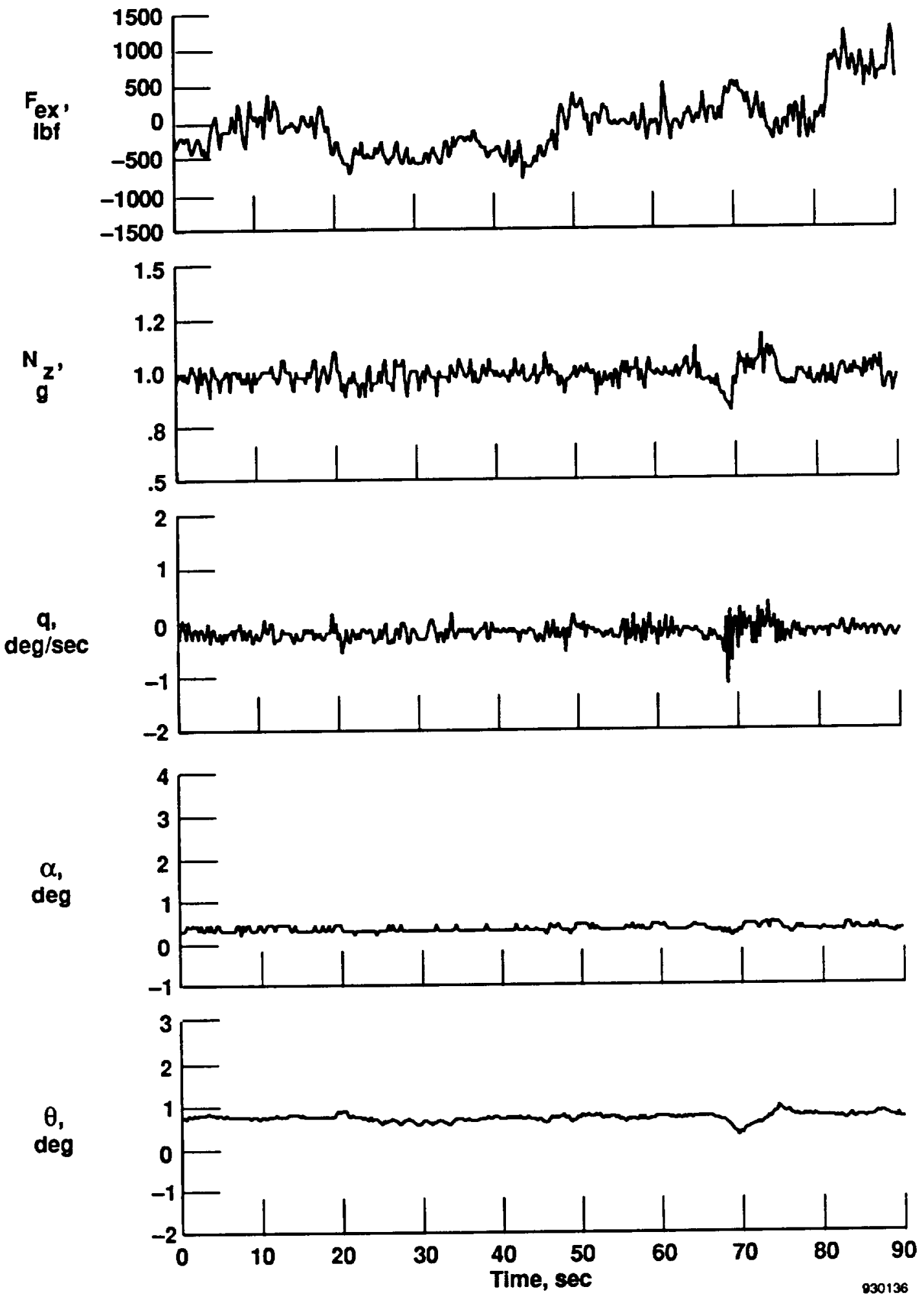

Fig. 9 Cowl perturbation time histories; Mach 1.25 at 25,000 ft. 

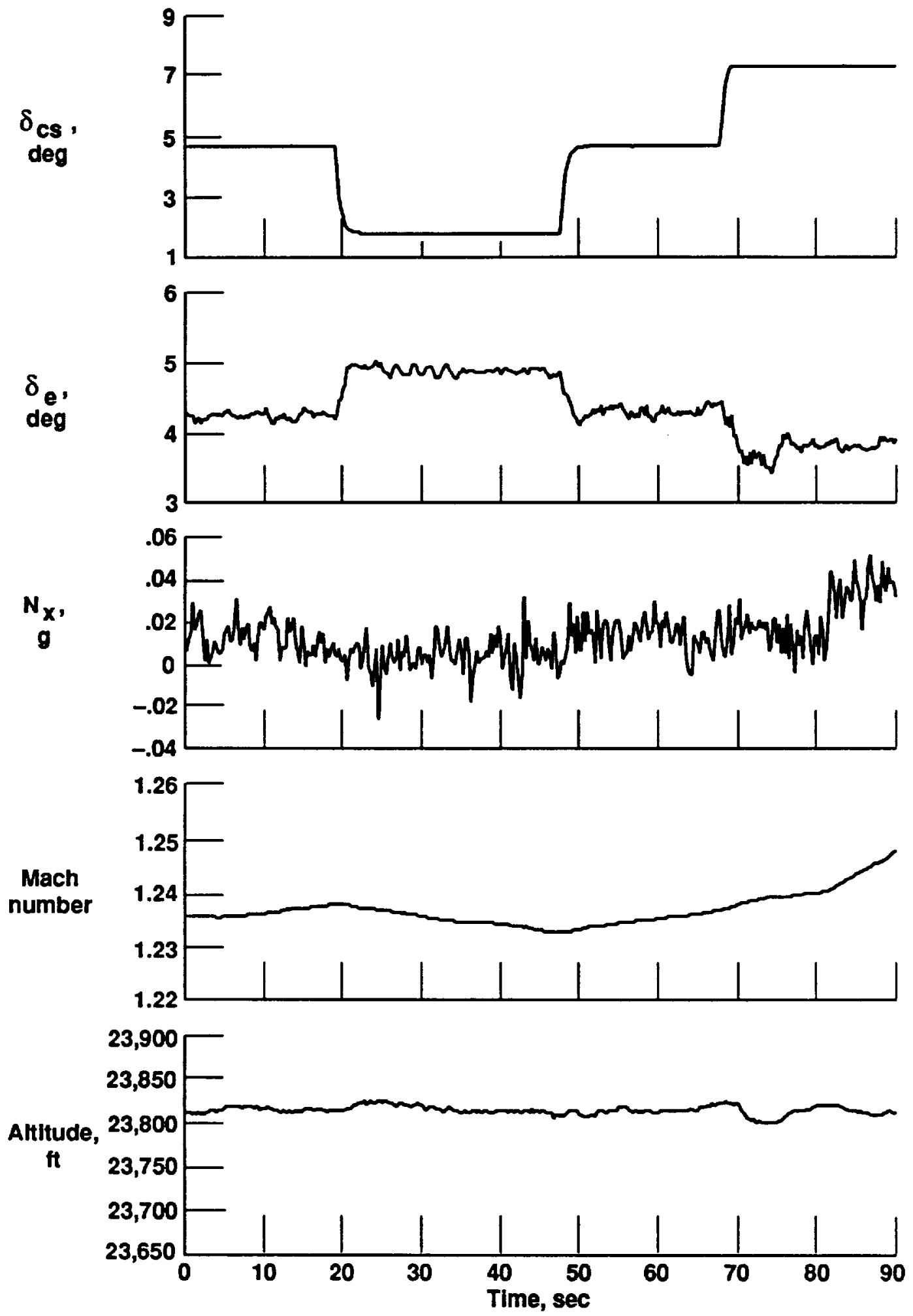

Fig. 9 Concluded. 


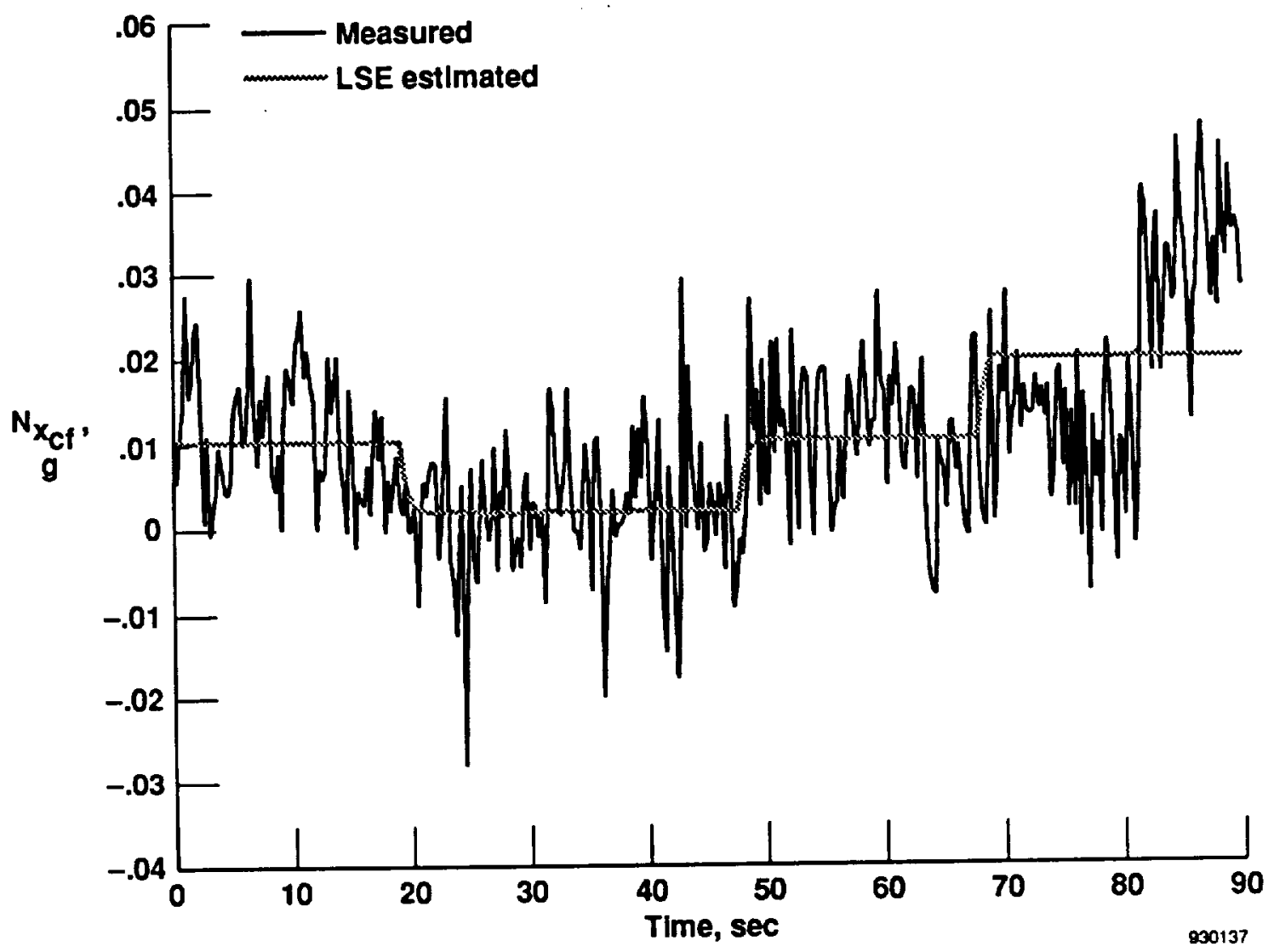

Fig. 10 Measured and computed time histories of $N_{x_{c f}}$ using the LSE algorithm; Mach 1.25 at 25,000 ft. 

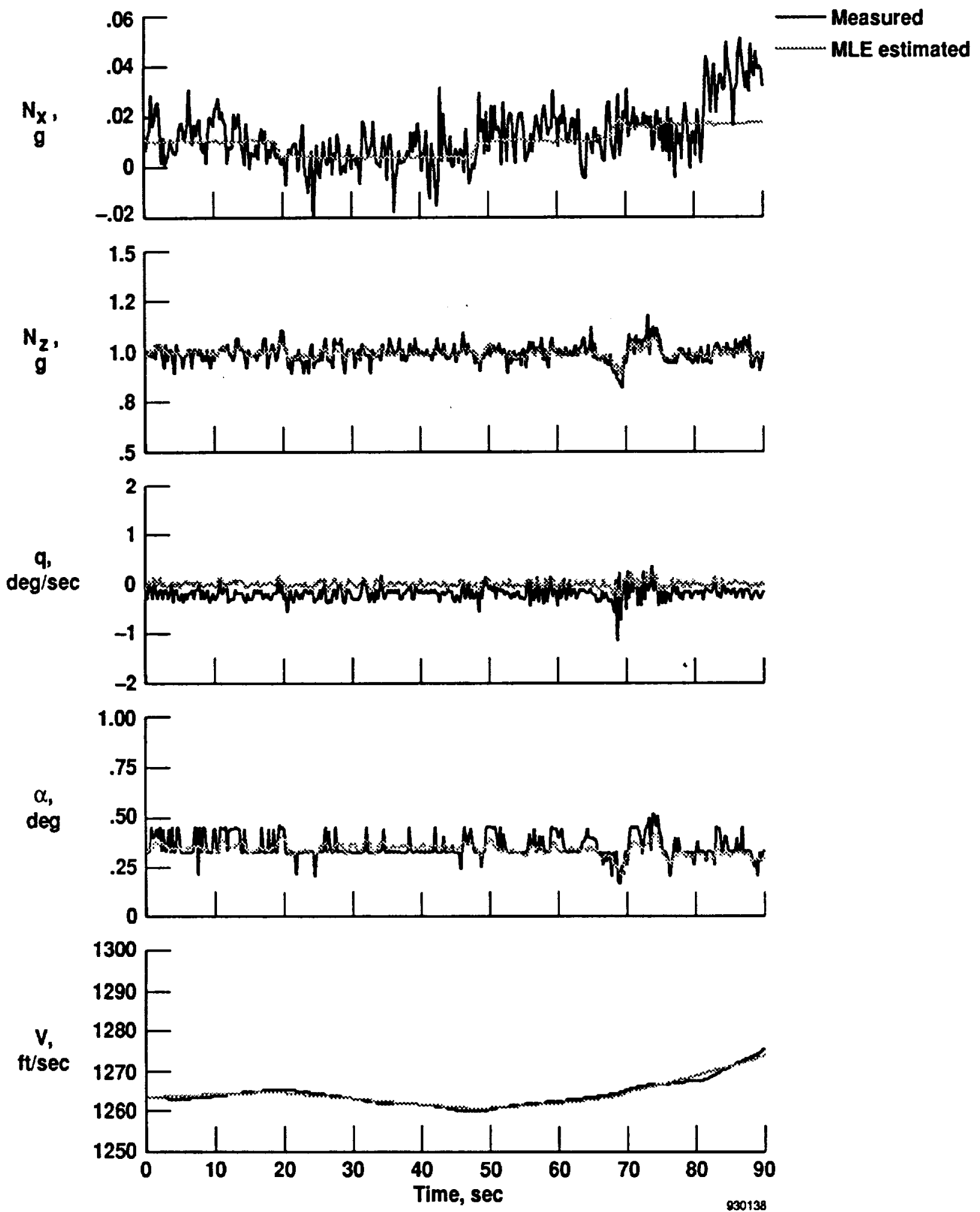

Fig. 11 Measured and computed time histories for cowl perturbation maneuver using the MLE algorithm; Mach 1.25 at $25,000 \mathrm{ft}$. 

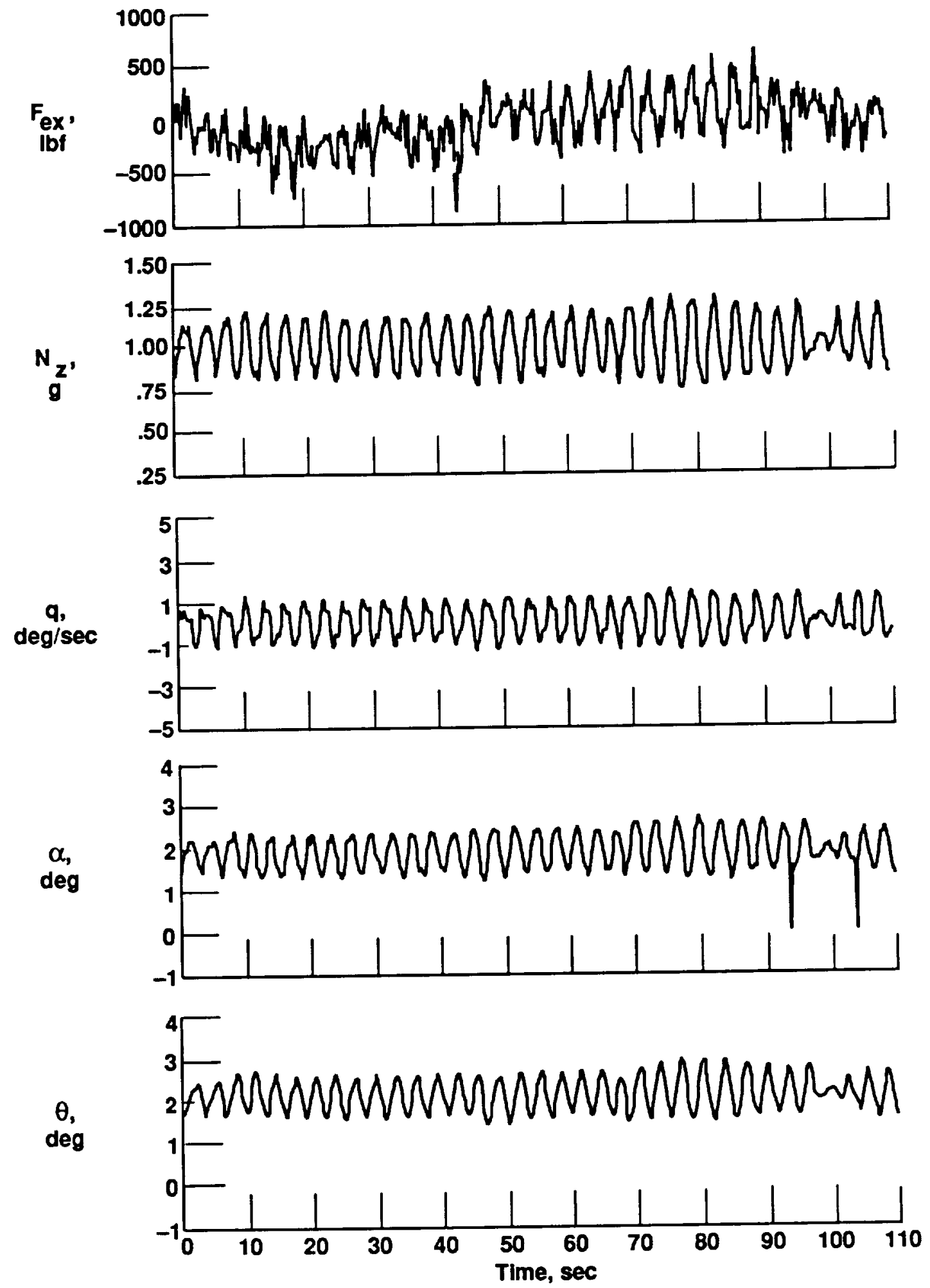

Fig. 12 Cowl perturbation time histories; Mach 0.85 at 35,000 ft. 

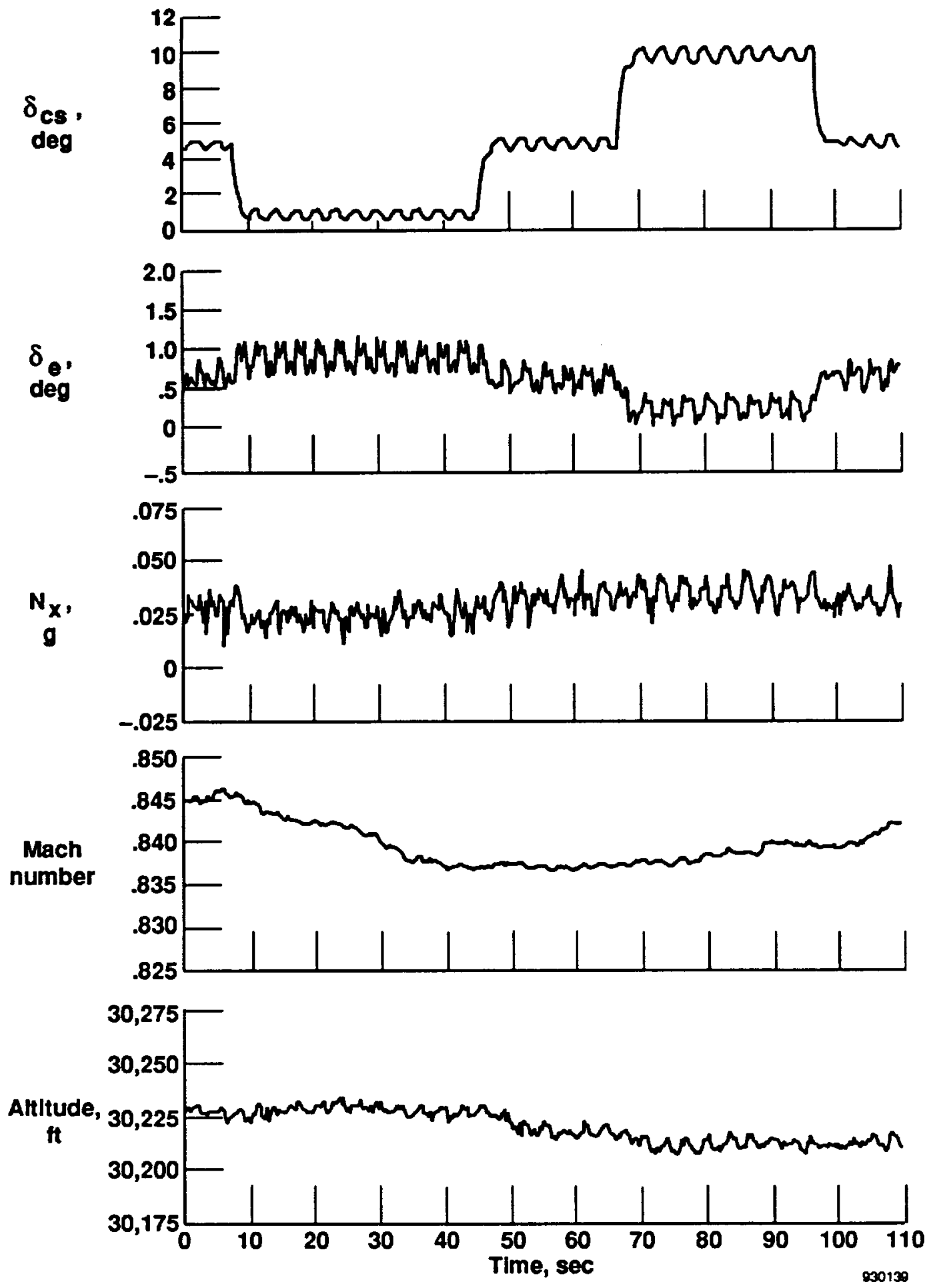

Fig. 12 Concluded. 


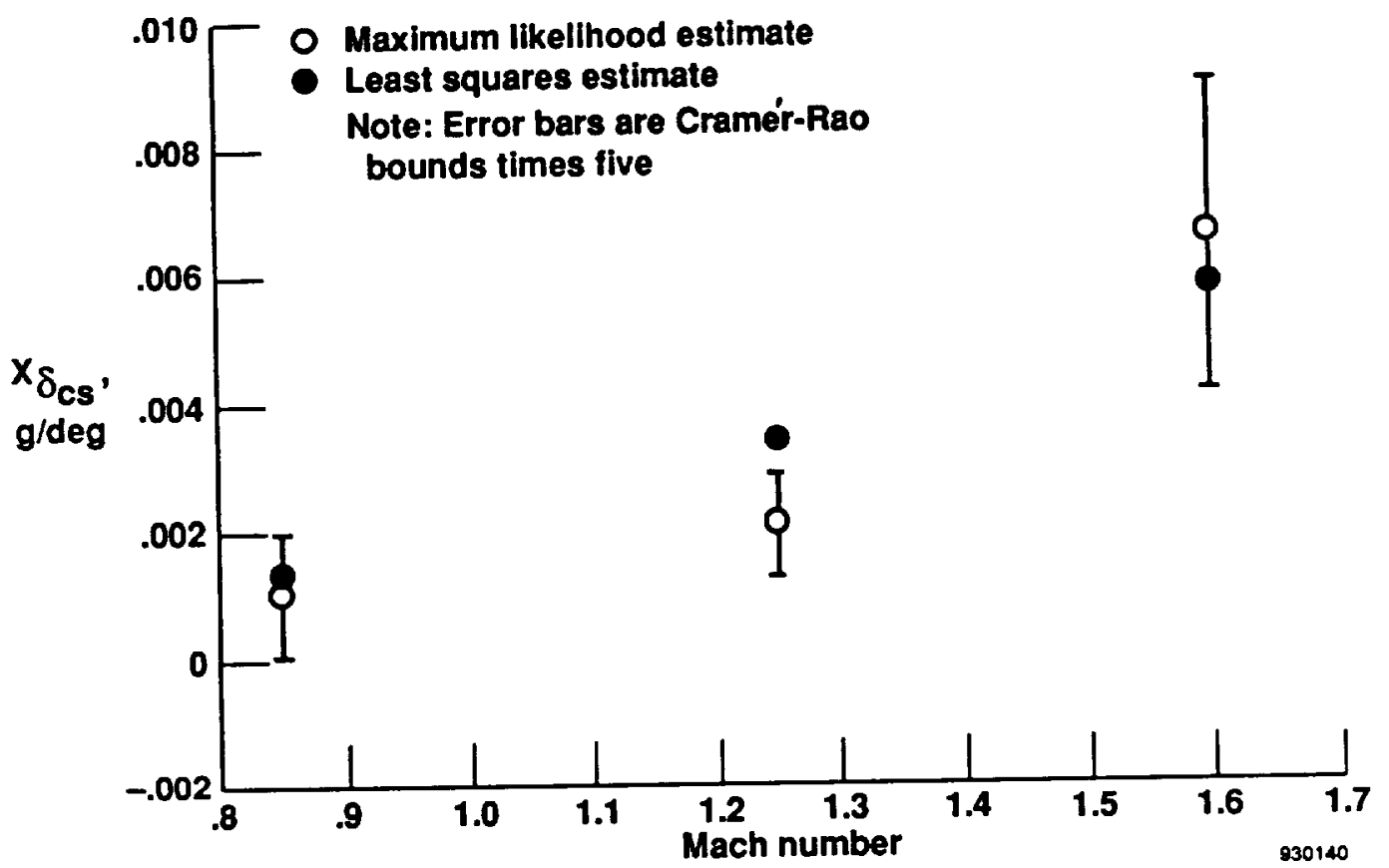

Fig. 13 Comparison of MLE and LSE results as a function of Mach number. 


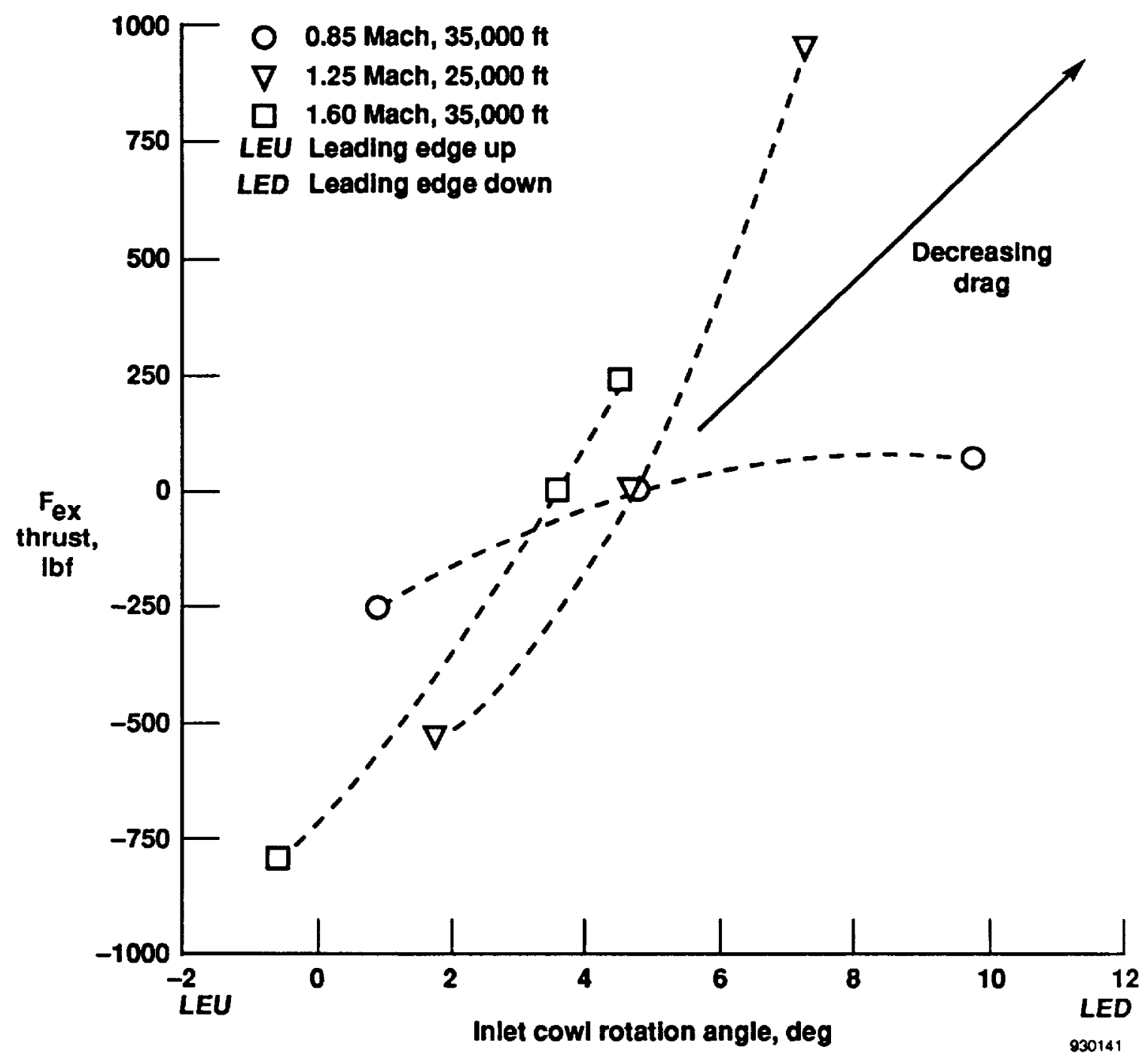

Fig. 14 Summary of measurement-based performance optimization feasibility study cowl perturbation.

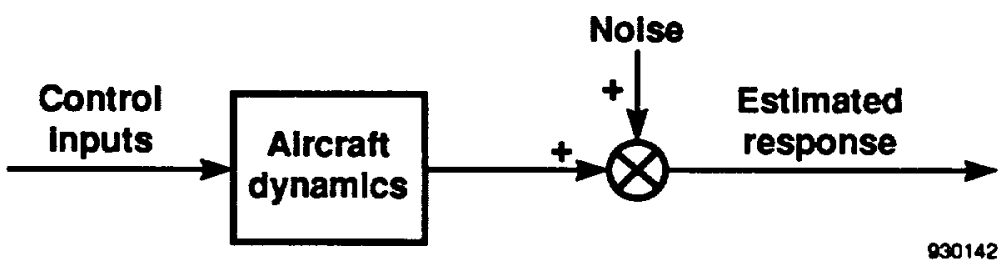

Fig. 15 The LSE autoregressive exogenous model. 



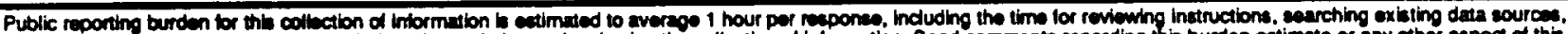

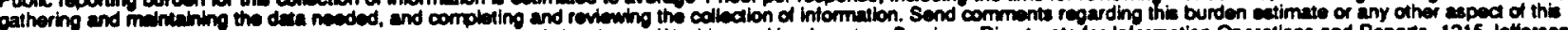

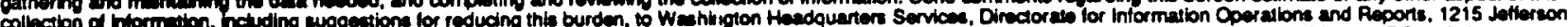

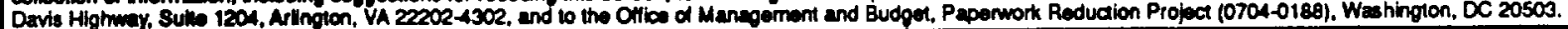

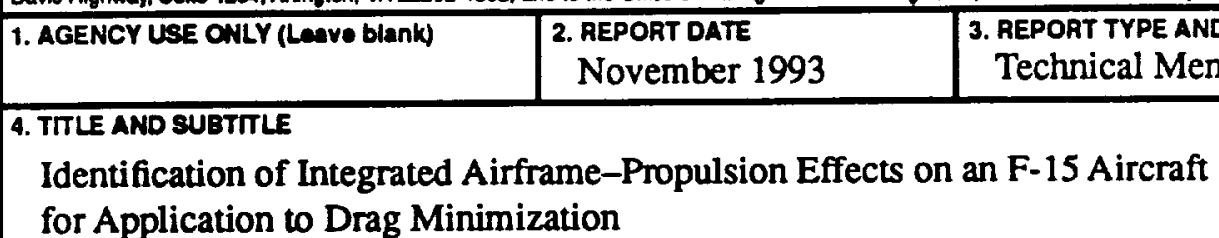

6. AUTHOR(S)

WU 533-02-39

Gerard S. Schkolnik

7. PERFORMING ORGANIZATION NAME(S) AND ADDRESS(ES)

NASA Dryden Flight Research Facility

P.O. Box 273

Edwards, California 93523-0273

B. PERFORMING ORGANIZATION REPORT NUMBER

H-1946

9. SPONSORINONONOTORING AGENCY MAME(S) AND ADDAESS(ES)

National Aeronautics and Space Administration

Washington, DC 20546-0001

10. SPONSORINGMONITORING AGENCY REPORT NUMBER

NASA TM-4532

\section{SUPPLEMENTAAY NOTES}

This paper was prepared as AIAA-93-3764 for the Guidance, Navigation, and Control Conference held August 9-11, 1993 in Monterey, California.

12a. DISTRIBUTIONAVAILABIUTY STATEMENT

12b. DISTRIBUTION CODE

Unclassified-Unlimited

Subject Category 07

13. ABSTRACT (Maximum 200 words)

The application of an adaptive real-time measurement-based performance optimization technique is being explored for a future flight research program. The key technical challenge of the approach is parameter identification, which uses a perturbation-search technique to identify changes in performance caused by forced oscillations of the controls. The controls on the NASA F-15 highly integrated digital electronic control (HIDEC) aircraft were perturbed using inlet cowl rotation steps at various subsonic and supersonic flight conditions to determine the effect on aircraft performance. The feasibility of the perturbation-search technique for identifying integrated airframe-propulsion system performance effects was successfully shown through flight experiments and postflight data analysis. Aircraft response and control data were analyzed postflight to identify gradients and to determine the minimum drag point. Changes in longitudinal acceleration as small as $0.004 \mathrm{~g}$ were measured, and absolute resolution was estimated to be $0.002 \mathrm{~g}$ or approximately $50 \mathrm{lbf}$ of drag. Two techniques for identifying performance gradients were compared: a least-squares estimation algorithm and a modified maximum likelihood estimator algorithm. A complementary filter algorithm was used with the least squares estimator.

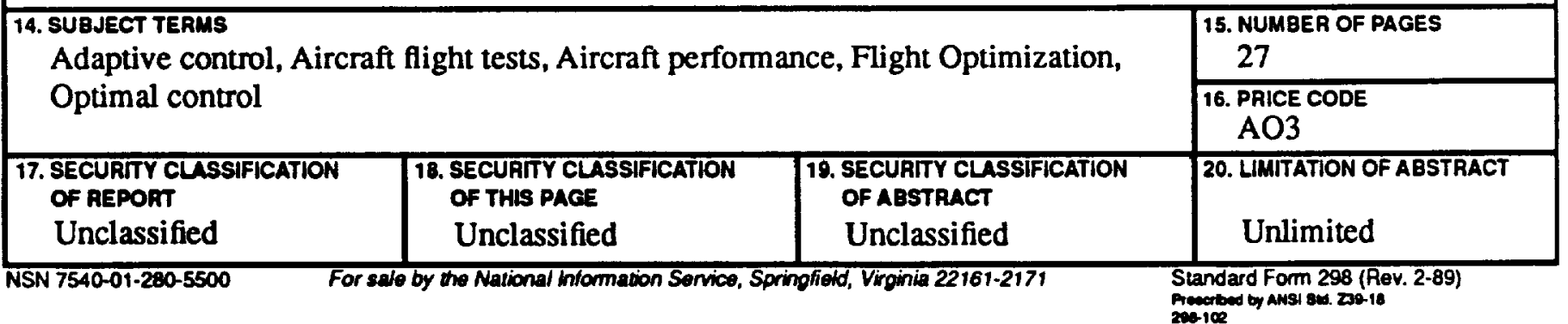

